\title{
La diversidad de agentes y la evolución de las patentes traslapadas en los vehículos eléctricos
}

\section{The diversity of agents and evolution of overlapping patents on electric vehicles}

\author{
Ricardo Artemio Chávez Meza* y Arturo Ángel Lara Rivero \\ Universidad Autónoma Metropolitana, México
}

Recibido el 22 de abril de 2014; aceptado el 16 de septiembre de 2015

Disponible en Internet el 12 de agosto de 2016

\begin{abstract}
Resumen
Este artículo estudia la actividad inventiva relacionada con los vehículos eléctricos. En particular examina la relación entre las patentes traslapadas y una población diversa de agentes: empresas, entidades no practicantes, inventores individuales y alianzas. Con base en la información de la Oficina de Patentes y Marcas de Estados Unidos (USPTO), período 1976-2012, se presenta: 1) a partir del análisis de redes, la creciente complejidad de la actividad inventiva de los vehículos eléctricos;2) las características y evolución de la actividad inventiva y 3) su relación con la existencia de patentes traslapadas. Se demuestra que la evolución de las patentes traslapadas (de menor a mayor complejidad) se asocia con una mayor complejidad del conocimiento tecnológico y con una mayor diversidad de agentes.

Derechos Reservados (C) 2016 Universidad Nacional Autónoma de México, Facultad de Contaduría y Administración. Este es un artículo de acceso abierto distribuido bajo los términos de la Licencia Creative Commons CC BY-NC-ND 4.0.
\end{abstract}

Códigos JEL: B52; C45; K11; K23; L24; L62; L63; O31; O34; P13; P14; P47

Palabras clave: Vehículos eléctricos; Patentes; Tecnología; Complejidad; Diversidad

\footnotetext{
* Autor para correspondencia.

Correos electrónicos: artemio79@ hotmail.com (R.A. Chávez Meza)
}

La revisión por pares es responsabilidad de la Universidad Nacional Autónoma de México. 


\begin{abstract}
This article studies the inventive activity related to electric vehicles. Particularly, examining the relationship between the overlapping patents and a diverse population of agents: Companies, non-practicing entities, individual inventors and alliances. Based on information from the United States Patent and Trademark Office (USPTO), period from 1976 to 2012, it is presented: 1) as from network analysis, the increasing complexity of inventive electric vehicles; 2) the characteristics and evolution of inventive activity and, 3) its relationship with the existence of overlapping patents. It is shown that the evolution of overlapping patents (from low to high complexity) is associated with greater complexity of technological knowledge as well as greater diversity of agents.
\end{abstract}

All Rights Reserved () 2016 Universidad Nacional Autónoma de México, Facultad de Contaduría y Administración. This is an open access item distributed under the Creative Commons CC License BY-NC-ND 4.0.

JEL classification: B52; C45; K11; K23; L24; L62; L63; O31; O34; P13; P14; P47

Keywords: Electric vehicles; Patents; Technology; Complexity; Diversity

\title{
Introducción
}

En la industria automotriz, la innovación es un proceso complejo multinivel. Esta característica se puede observar en la arquitectura de los vehículos eléctricos (VE) compuesta por distintos subsistemas $^{1}$, los cuales cumplen de manera coordinada múltiples funciones. Desde esta perspectiva, para innovar se requiere integrar numerosos subsistemas localizados en distintos niveles. En el nivel más profundo de la invención (Arthur, 2011), se encuentra el conocimiento de las leyes de la naturaleza que permite a los agentes resolver problemas asociados al diseño y desarrollo de nuevos VE, motores ${ }^{2}$, baterías avanzadas ${ }^{3}$, o los novedosos sistemas propios de este tipo de vehículos ${ }^{4}$. En otro nivel se encuentran los agentes que patentan: inventores independientes $^{5}$, empresas, centros de investigación, universidades, gobiernos y alianzas de estos mismos agentes ${ }^{6}$. Cada uno de estos agentes tiene intereses específicos. En otro nivel se

\footnotetext{
${ }^{1}$ Un automóvil convencional cuenta con alrededor de 10,000 piezas únicas, (Ulrich y Eppinger, 2009). Cuenta con 5 grandes subsistemas (powertrain, chasis, seguridad, confort e info-entretenimiento). Dependiendo del nivel de lujo tiene incorporado de 30 a 100 microcomputadoras (Juliussen y Robinson, 2010). Y desarrollar un nuevo modelo toma de 3 a 5 años (Bauer, 2007: 278).

${ }^{2}$ Entre los distintos motores que se han desarrollado se pueden identificar a 1) eléctricos puros; 2) híbridos (suaves, completos, paralelos y seriales), así como 3) al fuel cell (Roland Berger Consultants, 2009).

${ }^{3}$ Las baterías pueden clasificarse de distintas maneras: batería de arranque o tracción; o según sus materiales activos (plomo ácido, de níquel metal hidruro, de litio o de aire, etc.) (Pistoia, 2008; Lara y Salazar, 2013; Reyes, 2012).

${ }^{4}$ La batería de un vehículo eléctrico utiliza un sofisticado sistema de administración de energía (SAB), integrado por microcomputadoras, sensores, actuadores y un subsistema de enfriamiento (Pistoia, 2008) que optimiza la energía eléctrica necesaria para la tracción y el resto de las funciones del vehículo.

${ }^{5}$ En adelante se denominan solo como inventores.

${ }^{6}$ La comunidad de organizaciones que se vincula con la innovación tecnológica de los vehículos eléctricos es extensa. Están, entre otros: las oficinas de patentes; organismos de gobierno que incentivan o restringen el cambio tecnológico; consumidores; organizaciones no gubernamentales y tribunales. Nos centraremos solo en el subconjunto de agentes que están vinculados exclusivamente con la invención tecnológica para no complicar el alcance de nuestro estudio.
} 
encuentran las reglas institucionales, como los derechos de propiedad intelectual, en particular las patentes, que influyen sensiblemente en la actividad inventiva.

Estos 3 niveles, naturaleza del bien, atributos de los agentes y naturaleza de las reglas, son las variables exógenas de la situación de acción del marco de análisis y desarrollo institucional propuesto por Ostrom, 1990, Hess y Ostrom, 2003; Ostrom, 2005; Poteete, Janssen y Ostrom, 2011). Este programa analítico resulta útil para estudiar la evolución de la actividad inventiva, en particular, los dilemas asociados a las situaciones de acción que deben resolver los agentes cuando se enfrentan al problema de las patentes traslapadas (patent thicket).

Los VE utilizan una constelación amplia y compleja de tecnologías que ningún agente de manera aislada puede desarrollar. Por esta razón, la actividad inventiva, en la medida en que recombina conocimiento (y patentes) originado en otras organizaciones, puede crear una «densa red de derechos de propiedad traslapados que las empresas deben superar para innovar» (Shapiro, 2001: 120). Los derechos de propiedad traslapados se asocian frecuentemente a: 1) bienes complejos; 2) alta fragmentación de la tecnología; 3) imposibilidad de definir con precisión los límites del conocimiento relacionados con las patentes (Bessen y Maurer, 2008) lo que se agrava, 4) dada la naturaleza ambigua propia del lenguaje (Ostrom, 1980).

Las patentes traslapadas pueden resultar en costosos y dilatados procesos de negociación y, por ende, en sustanciales costos de transacción. En el extremo, pueden conducir a agentes rivales a bloquearse mutuamente e impedir de este modo el uso o explotación comercial de la tecnología. A este problema de subutilización de recursos se lo denomina «tragedia de los anticomunes» (Heller, 1998, 2008).

Las patentes traslapadas y la tragedia de los anticomunes se han estudiado en la industria biomédica (Heller y Eisenberg, 1998), en la genómica (Van Overwalle, 2009; Osorio y Lara, 2013) y en el sector automotriz (Chávez y Lara, 2014). Para Chávez y Lara (2014) la creciente complejidad de los VE (naturaleza del bien) contribuye a explicar el problema de las patentes traslapadas. Para avanzar en la naturaleza de las patentes traslapadas nuestro artículo examina el papel de la diversidad de agentes. Desde esta perspectiva, las preguntas centrales que guían este trabajo son: en la actividad inventiva de los VE ¿cómo evoluciona la diversidad de agentes?, ¿esta diversidad se corresponde con la evolución compleja de los VE? y ¿qué relación guarda esta diversidad de agentes con las patentes traslapadas?

La estructura del trabajo es la siguiente: en la primera sección se presenta una taxonomía de diversidad (Page, 2011) útil para representar la innovación tecnológica. En la segunda, con base en la información de la $\mathrm{USPTO}^{7}$, por medio de la construcción de la red de clases tecnológicas, se analiza la evolución de la actividad inventiva de los VE para el periodo 1976-2012. En la tercera sección, apoyados en indicadores cuantitativos, se examina la evolución de la diversidad tanto de los agentes como de los espacios de exploración tecnológica. Finalmente, apoyados en técnicas de análisis e indicadores de patentes traslapadas (IPO, 2011; Von Graevenitz, Stefan y Harhoff, 2011; Hall, Helmers, von Graevenitz y Bondibene, 2013) se estudia la relación de los espacios de exploración tecnológica con las patentes traslapadas ${ }^{8}$.

\footnotetext{
7 Oficina de Patentes y Marcas de Estados Unidos (USPTO, por sus siglas en inglés).

${ }^{8} \mathrm{Si}$ bien el alcance de este estudio es descriptivo, cuando la evidencia lo permite se presentan inferencias razonables sobre las relaciones causales de nuestras variables de estudio, a saber, la complejidad de la actividad inventiva de los vehículos eléctricos (representado por la red de clases tecnológicas) que se asocia con la diversidad de agentes (analizado con las distribución de patentes entre los agentes) y el problema de las patentes traslapadas (representado con medidas complementarias de distribuciones de clases tecnológicas, citas y patentes).
} 


\section{Complejidad y diversidad tecnológica}

Para Holland (2004) la diversidad se encuentra entre los 7 elementos básicos (mecanismos y propiedades) presentes en cualquier sistema complejo adaptable. ${ }^{9}$ Tanto Holland (2004) como Page (2011) y Low, Ostrom, Simon y Wilson (2003) consideran que la complejidad y la diversidad son recursivas (la diversidad genera complejidad y viceversa) y tienden a crear sistemas robustos.

La diversidad puede surgir al interior de un tipo (variación) $)^{10}$ o entre tipos ${ }^{11}$. Estas ideas se pueden representar por medio de cadenas binarias. Esto es, una tecnología se compone, por ejemplo, de 5 elementos ordenados en una cadena, y cada elemento tiene 2 posibles estados: 0 y 1 . La tecnología A se compone por la cadena $[0,0,0,0,0]$ y la tecnología B por la cadena $[0,0,1,1,1]$. Al difundirse una tecnología en un nicho específico puede dar lugar a una variación: emerge un nuevo tipo de tecnología. Por ejemplo, la cadena A en un ambiente particular muta su segundo elemento. De tal modo que ahora existirá una nueva tecnología $\mathrm{A}_{\mathrm{m}}$ con la cadena $[0,1,0,0,0]$. Ahora bien, si el ambiente favorece la reproducción de $\mathrm{A}_{\mathrm{m}} \mathrm{y}$ no la de $\mathrm{A}$, entonces crecerá y predominará la tecnología mutante $\mathrm{A}_{\mathrm{m}}$, en tanto que la tecnología $\mathrm{A}$ desaparecerá ${ }^{12}$. En su defecto, si la tecnología $A_{m}$ puede recombinarse con la tecnología $A$, entonces se amplía la diversidad. Si no es posible la recombinación de las cadenas de $\mathrm{A}$ y de $\mathrm{A}_{\mathrm{m}}$ entonces $\mathrm{A}_{\mathrm{m}}$ representa a una nueva tecnología (especie) ${ }^{13}$.

Kauffman (1993) construye un modelo de paisajes de aptitud en los que a cada variación se le asocia un nivel de aptitud, entendido como su tasa de reproducción. De tal modo que, en todo el espacio de posibilidades (todos los posibles estados de todos los elementos) se contará con un valor reproductivo para cada combinación y ello formará una especie de paisaje montañoso, en el que cada pico y valle representa el valor de aptitud. Así, los picos altos representan variaciones con alta reproducción y los valles, lo contrario. Frenken, Marengo y Valente (1999) y Frenken (2006) utilizan este modelo para estudiar la evolución de la tecnología.

Las tecnologías nuevas son variaciones de tecnologías anteriores. Las diversas tecnologías cumplen con distintas funciones. Por ejemplo, la tecnología A $[0,0,0,0,0]$ desempeña una función

\footnotetext{
${ }^{9}$ Los otros «básicos» son: la agregación, el marbeteo, los flujos, la no linealidad, los modelos internos y los bloques de construcción. En nuestro caso, solo nos concentraremos en el caso de la diversidad, por tratarse de nuestro tema de interés.

${ }^{10}$ Por ejemplo, la batería de litio tiene variaciones que generan diversidad intratipo de acuerdo al material activo utilizado en su cátodo: litio-titanio, litio-manganeso, litio-cobalto, etc.) (Reyes, 2012).

11 Por ejemplo, en los motores se puede observar diversidad entre tipos: motores de combustión interna, motores eléctricos o motores de hidrógeno.

12 Siguiendo las causas de diversidad al interior de un tipo de Page (2011) tenemos que: a) la mutación es un cambio aleatorio en el estado de un elemento, por ejemplo, la tecnología $A_{m}$ puede ser $[0,0,1,0,0]$ donde el tercer elemento de la tecnología A cambió, de tal modo que $\mathrm{A}_{\mathrm{m}}$ es una mutación de $\mathrm{A}$; b) la inversión es el cambio inverso del orden de los elementos, la inversión de la tecnología $\mathrm{A}, \mathrm{A}_{\mathrm{i}}$, es la propia tecnología $\mathrm{A}$, puesto que $[0,0,0,0,0]$ es la misma tecnología que $[0,0,0,0,0]$, pero en el caso de la tecnología $\mathrm{B}$, no pasa el mismo efecto: la inversión de $\mathrm{B}$ es $[1,1,1,0,0]$ donde el primer elemento cambia de orden con el último, el segundo con el penúltimo y así sucesivamente, de tal modo que $\mathrm{B}_{\mathrm{i}}$, es una variación de B; c) la recombinación se presenta cuando 2 cadenas se cruzan para formar otras, por ejemplo, A y B se pueden recombinar en su cuarto elemento, es decir, los 4 primeros elementos de A se combinan con el último elemento de B y los primeros 4 de $\mathrm{B}$ con el quinto de $\mathrm{A}$, las variaciones resultantes son: $[0,0,0,0,1]$ y $[0,0,1,1,0]$, donde ambas cadenas resultantes son una recombinación de las cadenas madre; d) la transferencia sucede cuando algún o algunos elementos de una cadena se transfieren a la otra, por ejemplo, los 3 primeros elementos de A se transfieren a B, el resultado es la cadena $[0,0,0,1,1]$ y e) finalmente, la diversidad representacional es una combinación simultánea de las otras causas.

13 En las 6 causas que generan diversidad entre tipos subyace esta misma lógica de selección, pero con sus respectivas particularidades.
} 
$\mathrm{F}_{\mathrm{A}} \mathrm{y}$ una variación de esta, la tecnología $\mathrm{A}_{1}[0,1,1,0,0]$ cumple con la función $\mathrm{F}_{\mathrm{A} 1}$, pero también con la función $\mathrm{F}_{\mathrm{A}}$. De este modo, los elementos de una tecnología pueden relacionarse de múltiples formas con diversas funciones. Las posibilidades combinatorias son prácticamente infinitas y la búsqueda de una tecnología óptima es, por lo demás, imposible. Por esta razón es por lo que coexisten en distintos nichos diversas tecnologías. A esta complejidad debe añadirse el que un sistema tecnológico desempeña múltiples funciones. Algunas de ellas pueden ser ejecutadas por tecnologías rivales o sustitutas, en tanto que otras requieren que se ensamblen tecnologías complementarias. En esta red de relaciones de rivalidad y complementariedad tecnológica radica una parte importante de la naturaleza de la actividad inventiva.

Ahora bien, una tecnología está limitada por las leyes de la naturaleza (Arthur, 2011). En la búsqueda de nuevas soluciones, una tecnología puede ser mejorada hasta alcanzar un límite físico que empuja a explorar otras tecnologías. Por ejemplo, en su primer vehículo eléctrico (EV1), la empresa General Motors mejora la batería de plomo ácido utilizada en los vehículos de motor a combustión. Las mejoras introducidas, sin embargo, son insuficientes: no cubren los requerimientos de un VE que necesita un sistema de acumulación de energía con propiedades de carga/descarga profunda. El desempeño de esta batería es pobre.

Como resultado de esta experiencia, los diseñadores de VE buscan nuevas soluciones: explorar otros materiales activos (baterías de litio-ion, $\mathrm{NiMH}$, etc.) u otros dominios de conocimiento (por ejemplo, la tecnología de fuel cell). Así, cuando la mejora no es suficiente se requiere una exploración más amplia, lo cual implica que: a) el descubrimiento de una solución genera nuevos problemas (Ostrom, 1980, Simon, 1996) que pueden conducir a la profundización estructural de la tecnología, esto es, a la emergencia de subsistemas dentro de subsistemas (Arthur, 2011) ${ }^{14}$ y b) los nuevos sistemas necesitan interactuar con los viejos, es decir, se requiere de interfaces adecuadas $^{15}$.

Cabe preguntarse cómo, a partir de la base de datos de la USPTO, es posible examinar la relación entre la complejidad tecnológica de los VE y la diversidad de los agentes inventores. Lo primero se aborda en la siguiente sección y lo segunda, en la subsecuente.

\section{Complejidad en la invención de los vehículos eléctricos}

Una forma de aproximarnos a la complejidad tecnológica de los VE es por medio de las patentes. Estas brindan abundante información sobre las áreas de investigación de cada inventor. Dichas áreas de exploración se pueden representar mediante las clases tecnológicas ${ }^{16}$. Las patentes ponen en evidencia la importancia que tiene para cada agente el conocimiento que desarrolla ${ }^{17}$. Y también pueden indicar la transferencia de conocimiento entre agentes.

\footnotetext{
${ }^{14}$ Por ejemplo, la batería de los vehículos eléctricos requiere, a diferencia de los vehículos convencionales, un sistema de enfriamiento, microcomputadoras que administren la energía, sensores, software especializado, actuadores, sistemas de monitoreo electrónicos, etc. (Pistoia, 2008).

15 Por ejemplo, en el desarrollo de los vehículos eléctricos, se requiere de una alta interconectividad rápida y confiable en prácticamente todos los subsistemas del vehículo (Juliussen y Robinson, 2010).

16 Todas las patentes están clasificadas según el área de conocimiento técnico a la que pertenecen. Cada oficina de patentes tiene su propia clasificación y una adicional que pertenece a la Organización Mundial de la Propiedad Intelectual (WIPO, por sus siglas en inglés). Así, cuando se hace referencia a la clase se indica con ello el dominio tecnológico al que pertenece una patente.

17 Hay muchas razones por las cuales un agente patenta, que van desde la protección de su conocimiento hasta motivaciones estratégicas (Blind, Edler, Frietsch y Schmoch, 2006).
} 


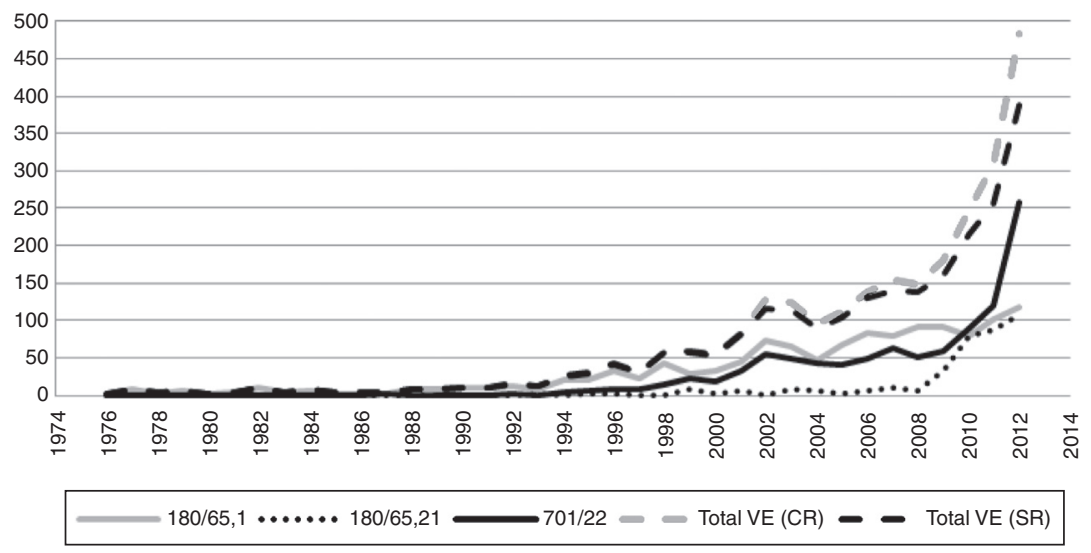

Figura 1. Patentes de vehículos eléctricos (1976-2012)

Fuente: Elaboración propia, información obtenida de la USPTO. Base de datos UAM/PECCI. Proyecto «Sistemas Complejos Adaptables y Cooperación Tecnológica» CONACyT No. I0017-156204.

Nota: Todas las patentes incluyen alguna de las clases buscadas y algunas patentes pueden incluir más de una de las clases buscadas. El total con repeticiones (CR) incluye las repeticiones y el total sin repeticiones (SR), las excluye.

Nuestro estudio utiliza la información de las patentes relacionadas con los VE de la USPTO porque es una base de datos confiable y accesible; y porque las empresas de la industria automotriz buscan proteger su actividad inventiva en el mercado estadounidense, que es uno de los más importantes del mundo ${ }^{18}$. De esta base de datos se seleccionaron las patentes que pertenecen a las clases: 180/65.1, 180/65.21 y 701/22. Se eligieron estas clases porque la oficina de patentes de la USPTO considera que la invención de los VE está contenida en dichas clases ${ }^{19}$. La base de datos cuenta con 2,358 patentes otorgadas, que van desde el $1 .^{\circ}$ de enero de 1976 hasta el 17 de noviembre de $2012^{20}$.

Con esta información es posible observar ( $c f$. fig. 1) 2 características relevantes de la actividad inventiva asociada a los VE. En primer lugar, desde 1992, el crecimiento en el número de patentes otorgadas ha sido exponencial. Fenómeno estrechamente asociado a los cambios en materia de legislación ambiental y a la variación de los precios del petróleo (Lara, 2014). En segundo lugar, desde 2009, el crecimiento acelerado de la clase 701/22 (Data processing: vehicles, navigation, and relative location; electric vehicle) que iguala (2010) y luego supera (2012) el número de patentes de la clase 180/65.1 (Motor vehicles; electric power). Esta migración de la actividad inventiva concentrada en el motor eléctrico (componente tangible) al procesamiento de datos

\footnotetext{
18 Disponible en: http://www.uspto.gov/web/patents/classification/international/est_concordance.htm, consultada el 20 de noviembre de 2012.

19 Cf. Environmentally Sound Technologies (ETS) Concordance. USPTO (s/f).

20 Es importante señalar que estas patentes incluyen a todos los vehículos eléctricos, es decir, no solo a los propios de la industria automotriz sino también a los vehículos terapéuticos como sillas de ruedas eléctricas o vehículos eléctricos montables para niños. Este tipo de vehículos no son retirados del análisis por 2 razones: 1) se sesgaría la base con un criterio diferente y subjetivo al que se construyó y 2) se elimina la posibilidad de observar relaciones posibles entre este tipo de productos y los vehículos elécricos propios de la industria automotriz. La base incluye, además del número de la patente, los siguientes datos: el año en que fue otorgada la patente, el año en el que fue solicitada la patente, el número de citas forward, el número de citas backward, el nombre del inventor, el número de inventores, el nombre del asignatario de la patente, el número de reivindicaciones de la patente, el país de origen, las clases tecnológicas, el número de clases tecnológicas y el número de inventores.
} 


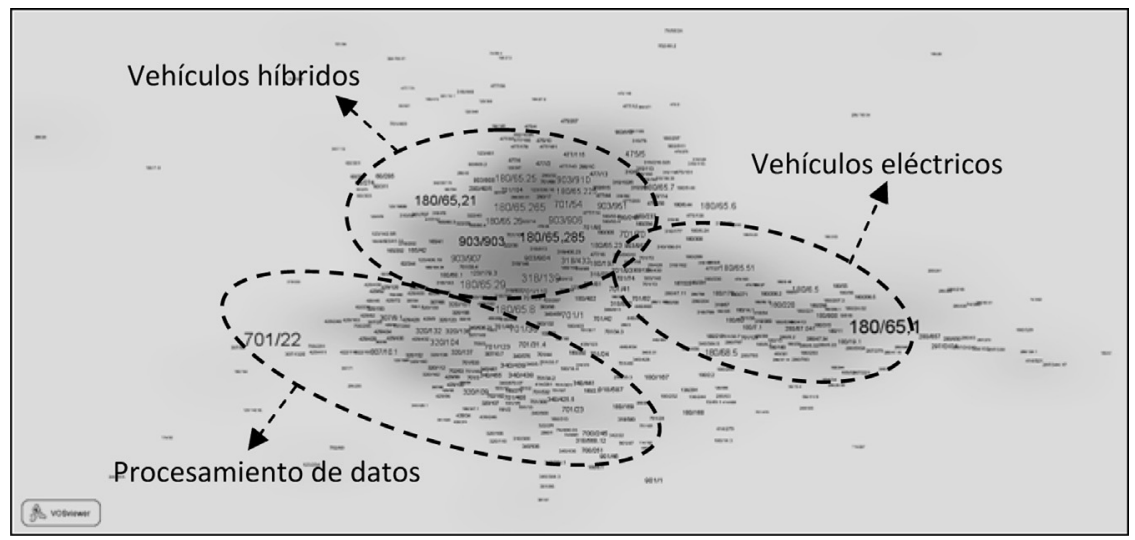

Figura 2. Red de clases de los vehículos eléctricos (1976-2012).

Fuente: ibid.

(componente intangible) da cuenta de la transformación cuantitativa y cualitativa de los procesos de invención y, en consecuencia, de la naturaleza del VE.

Como se señaló en la sección anterior, una tecnología se compone de elementos que se interrelacionan de forma particular ${ }^{21}$. Así, cada patente tiene asociada una cadena en la que sus elementos son las clases. Por lo tanto, una cadena larga significa un conocimiento especializado y una corta, un conocimiento relativamente genérico ${ }^{22}$. Cuando 2 patentes comparten una clase tecnológica se crea un vínculo; entonces es posible construir una red de clases ${ }^{23}$. La figura 2 ilustra la red de clases de los VE del periodo 1976-2012. El área de la red de color más oscuro indica una mayor densidad de la red, es decir, las clases tienen un mayor grado de conectividad, en tanto que los colores más claros indican una menor conexión. Las clases más conectadas se encuentran asociadas a los vehículos híbridos y, en menor medida, a las clases de los VE. La menos conectada, probablemente por su juventud, son las clases de procesamiento de datos. Las estadísticas de esta red se encuentran en la tabla 1.

En la primera columna de la tabla 1 se muestra el número de nodos. En nuestro caso, el número de clases tecnológicas utilizadas cada año. De 8 clases en 1976 crece, de manera exponencial, a 2,394 clases en 2012. Esto significa que los agentes han explorado el espacio de diseño con un

\footnotetext{
${ }^{21}$ Las clases de las patentes pueden representar el tipo de conocimiento particular contenido en la patente, por ejemplo, si una patente cuenta con las clases 340/455 (Communications: electrical [... I indicator responsive to a condition of the vehicle, Battery charging systems) y la clase 701/22 (Data processing: vehicles, navigation, and relative location; electric vehicle) se trata de una invención relacionada con el procesamiento de datos para indicar el estado de la batería o del vehículo.

22 En la sección anterior se explicó que una tecnología puede ser representada por una cadena binaria de componentes (por ejemplo, la tecnología $\mathrm{T}$ se puede representar por la cadena $[0,1,0,1,0]$. En el caso de las patentes, cada patente es clasificada y de acuerdo a su clasificación se puede generar una cadena de clases que representa un área de conocimiento específica, pero, en lugar de utilizar los estados binarios 0 y 1, se sustituye por la clave de su clasificación. Por ejemplo, la patente número 4124086 cuenta con 2 clases tecnológicas la 180/65.1 y la 310/219, es decir, forma la cadena [180/65.1, 310/219] y la patente 4364444 cuenta con 5 clases tecnológicas que pueden representarse por medio de la cadena [180/65.1, 165/104.34, 237/12.3A, 361/694, 454/75]. Una cadena más larga implica que el conocimiento que contiene es más complejo en el sentido de que incluye muchas áreas de conocimiento, mientras que una cadena más corta significa que el conocimiento contenido en esa patente requiere de menos áreas de conocimiento y, por lo tanto, es más genérica. 23 Para una revisión más profunda del significado e interpretación de estos estadísticos ver Chávez y Lara (2014) y para detalles de la construcción de la red ver el Anexo 1.
} 
Tabla 1

Estadísticas de las redes de los VE (1976-2012)

Estadísticos de las redes

\begin{tabular}{|c|c|c|c|c|c|c|c|c|c|c|c|}
\hline Año & Nodos & $\begin{array}{l}\text { Enlaces } \\
\text { únicos }\end{array}$ & $\begin{array}{l}\text { Enlaces } \\
\text { duplicados }\end{array}$ & $\begin{array}{l}\text { Total de } \\
\text { enlaces }\end{array}$ & Nodos/enlaces & Auto-loops & Diámetro & $\begin{array}{l}\text { Distancia } \\
\text { geodésica } \\
\text { promedio }\end{array}$ & Grupos & Densidad & Modularidad \\
\hline$\overline{1976}$ & 8 & 16 & 0 & 16 & 0.5 & 0 & 2 & 1.25 & 2 & 0.571428571 & 0.25 \\
\hline 1977 & 30 & 85 & 9 & 94 & 0.352941176 & 0 & 2 & 1.735556 & 4 & 0.204597701 & 0.453259 \\
\hline 1978 & 49 & 170 & 48 & 218 & 0.288235294 & 0 & 3 & 1.96918 & 4 & 0.159863946 & 0.430267 \\
\hline 1979 & 63 & 208 & 41 & 249 & 0.302884615 & 2 & 3 & 2.025699 & 6 & 0.115719406 & 0.48352 \\
\hline 1980 & 73 & 251 & 52 & 303 & 0.290836653 & 2 & 3 & 2.034903 & 7 & 0.104261796 & 0.494834 \\
\hline 1981 & 94 & 333 & 58 & 391 & 0.282282282 & 2 & 3 & 2.044817 & 7 & 0.081903455 & 0.542813 \\
\hline 1982 & 143 & 527 & 80 & 607 & 0.271347249 & 2 & 3 & 2.092327 & 11 & 0.055254605 & 0.588207 \\
\hline 1983 & 160 & 577 & 84 & 661 & 0.27729636 & 2 & 3 & 2.085469 & 11 & 0.048113208 & 0.582982 \\
\hline 1984 & 188 & 708 & 99 & 807 & 0.265536723 & 2 & 3 & 2.096084 & 12 & 0.042610081 & 0.579435 \\
\hline 1985 & 198 & 729 & 103 & 832 & 0.271604938 & 2 & 4 & 2.170442 & 12 & 0.039583654 & 0.587072 \\
\hline 1986 & 209 & 777 & 117 & 894 & 0.268983269 & 2 & 4 & 2.217165 & 13 & 0.038001472 & 0.605873 \\
\hline 1987 & 223 & 858 & 131 & 989 & 0.25990676 & 2 & 4 & 2.287036 & 11 & 0.036884418 & 0.594135 \\
\hline 1988 & 253 & 996 & 153 & 1,149 & 0.254016064 & 2 & 4 & 2.261994 & 12 & 0.033189033 & 0.586849 \\
\hline 1989 & 271 & 1,056 & 185 & 1,241 & 0.256628788 & 2 & 4 & 2.27151 & 10 & 0.030859642 & 0.583661 \\
\hline 1990 & 280 & 1,086 & 281 & 1,367 & 0.257826888 & 2 & 4 & 2.257423 & 12 & 0.030363543 & 0.547263 \\
\hline 1991 & 297 & 1,132 & 328 & 1,460 & 0.262367491 & 2 & 4 & 2.216327 & 12 & 0.028301028 & 0.537372 \\
\hline 1992 & 336 & 1,327 & 400 & 1,727 & 0.253202713 & 2 & 4 & 2.208493 & 14 & 0.025852878 & 0.514947 \\
\hline 1993 & 356 & 1,431 & 498 & 1,929 & 0.248777079 & 2 & 3 & 2.209964 & 14 & 0.02522551 & 0.487046 \\
\hline 1994 & 402 & 1,656 & 635 & 2,291 & 0.242753623 & 2 & 3 & 2.197842 & 17 & 0.023051823 & 0.479149 \\
\hline 1995 & 441 & 1,776 & 804 & 2,580 & 0.248310811 & 2 & 3 & 2.208997 & 18 & 0.020902907 & 0.463507 \\
\hline 1996 & 535 & 2,232 & 1,023 & 3,255 & 0.239695341 & 2 & 3 & 2.193261 & 19 & 0.017858518 & 0.455203 \\
\hline 1997 & 585 & 2,479 & 1,105 & 3,584 & 0.235982251 & 3 & 3 & 2.221866 & 20 & 0.016496897 & 0.470099 \\
\hline 1998 & 662 & 2,908 & 1,442 & 4,350 & 0.227647868 & 3 & 3 & 2.21514 & 30 & 0.015302275 & 0.444439 \\
\hline 1999 & 744 & 3,617 & 2,758 & 6,375 & 0.205695328 & 3 & 3 & 2.263647 & 24 & 0.015680401 & 0.416215 \\
\hline 2000 & 811 & 4,068 & 3,296 & 7,364 & 0.199360865 & 3 & 3 & 2.270525 & 24 & 0.014948775 & 0.399082 \\
\hline 2001 & 910 & 4,943 & 4,426 & 9,369 & 0.184098725 & 4 & 3 & 2.272018 & 29 & 0.014584316 & 0.348095 \\
\hline 2002 & 1,082 & 6,709 & 6,456 & 13,165 & 0.161275898 & 5 & 3 & 2.264341 & 37 & 0.013995735 & 0.344776 \\
\hline 2003 & 1,230 & 7,789 & 8,121 & 15,910 & 0.157915008 & 6 & 3 & 2.291008 & 39 & 0.012570204 & 0.339868 \\
\hline 2004 & 1,294 & 8,325 & 9,338 & 17,663 & 0.155435435 & 7 & 3 & 2.286256 & 50 & 0.012208169 & 0.318373 \\
\hline 2005 & 1,392 & 9,021 & 10,409 & 19,430 & 0.154306618 & 9 & 3 & 2.279286 & 73 & 0.011487022 & 0.327287 \\
\hline 2006 & 1,473 & 9,623 & 11,210 & 20,833 & 0.153070768 & 10 & 3 & 2.272887 & 50 & 0.010941512 & 0.326016 \\
\hline 2007 & 1,587 & 10,396 & 11,979 & 22,375 & 0.152654867 & 11 & 3 & 2.287462 & 37 & 0.010147073 & 0.335135 \\
\hline 2008 & 1,662 & 11,069 & 12,982 & 24,051 & 0.150149065 & 15 & 3 & 2.278327 & 47 & 0.009893566 & 0.318214 \\
\hline 2009 & 1,800 & 12,348 & 14,658 & 27,006 & 0.145772595 & 17 & 3 & 2.270465 & 51 & 0.00948984 & 0.329608 \\
\hline 2010 & 1,922 & 13,682 & 16,634 & 30,316 & 0.140476539 & 24 & 3 & 2.280906 & 53 & 0.009272074 & 0.316975 \\
\hline 2011 & 2,124 & 15,957 & 19,115 & 35,072 & 0.133107727 & 33 & 3 & 2.281611 & 51 & 0.008828072 & 0.311535 \\
\hline 2012 & 2,394 & 19,669 & 23,895 & 43,564 & 0.121714373 & 57 & 3 & 2.277313 & 36 & 0.008603135 & 0.303294 \\
\hline
\end{tabular}

Fuente: ibid. 
Tabla 2

Participación y diversidad cualitativa del conocimiento de los agentes

\begin{tabular}{|c|c|c|c|c|c|c|c|c|}
\hline \multirow[t]{2}{*}{ Agente } & \multicolumn{3}{|c|}{ Participación de los agentes } & \multicolumn{5}{|c|}{ Indicadores promedio } \\
\hline & $\begin{array}{l}\text { Número } \\
\text { de } \\
\text { agentes }\end{array}$ & Patentes & $\begin{array}{l}\% \text { de } \\
\text { patentes }\end{array}$ & Reivindicaciones & $\begin{array}{l}\text { Citas } \\
\text { forward }\end{array}$ & $\begin{array}{l}\text { Citas } \\
\text { backward }\end{array}$ & $\begin{array}{l}\text { Número } \\
\text { de clases }\end{array}$ & $\begin{array}{l}\text { Número de } \\
\text { inventores }\end{array}$ \\
\hline Empresas & 350 & 1,865 & 79.09 & 15.22 & 8.2 & 18.71 & 5.55 & 2.66 \\
\hline Alianzas & 25 & 98 & 4.16 & 13.78 & 3.56 & 74.68 & 5.23 & 3.35 \\
\hline ENP & 35 & 78 & 3.31 & 17.23 & 16.67 & 25.3 & 5.61 & 2.96 \\
\hline Inventores & 271 & 317 & 13.44 & 13.57 & 12.26 & 15.45 & 4.57 & 1.3 \\
\hline Promedio & & & & 15 & 8.83 & 20.82 & 5.41 & 2.52 \\
\hline
\end{tabular}

Fuente: ibid.

mayor número de bloques de construcción (clases). También creció, de 16 a 19,669, el número de enlaces en todo el periodo. Sin embargo, si se observa la densidad de la red (el cociente entre el total de vínculos existentes y el total de vínculos posibles), esta es cada vez menor: de 0.571 (1976) disminuye a 0.008 (2012). Esto significa que las posibles combinaciones de clases son enormes, sin embargo, solo se ha explorado en una parte relativamente pequeña de la red, concentrada en algunas áreas específicas, lo cual es característico de un sistema complejo. La columna de la modularidad confirma este hecho. Este conjunto de estadísticas de la red de clases ayuda a explicar cómo la actividad inventiva de los VE es cada vez más compleja. Cabe preguntarse ahora ¿qué relación tiene esta complejidad con la composición de los agentes que patentan?

\section{Diversidad de agentes}

\section{Tipos de agentes y sus características generales}

El conocimiento contenido en las patentes es, en última instancia, producto del trabajo humano. Por ello resulta crucial comprender, de la organización de este trabajo, 2 características: a) si es resultado del ingenio individual o del trabajo colectivo y b) si existe una organización con capacidad para lidiar con las reglas de propiedad intelectual y para transformar las invenciones en innovaciones.

La oficina de patentes ${ }^{24}$ asigna derechos de propiedad intelectual a una clase amplia de agentes: inventores, empresas, entidades no practicantes ${ }^{25}$ (ENP) y alianzas entre estos. Estas categorías son útiles para caracterizar los atributos de los agentes, en particular, la diversidad de intenciones económicas y no económicas al patentar. En el caso de los VE el principal tipo de organización que patenta es el compuesto por empresas: el $79 \%$ de las patentes pertenece a 350 empresas. El $13 \%$ a 271 inventores; el $4 \%$ a 25 alianzas y el $3 \%$ a 35 ENP ( $c f$. tabla 2 ).

Además de la diversidad en las intenciones de los agentes, existen diferencias cuantitativas y cualitativas respecto al tipo de conocimiento que contribuye cada categoría de agente a la actividad

\footnotetext{
${ }^{24}$ Toda patente es asignada a una persona u organización (assigneer) que le garantiza el derecho de propiedad intelectual en el país donde registra su patente.

25 Las entidades no practicantes (ENP) son organizaciones que tienen patentes asignadas, pero que usualmente no utilizan para sí mismas las tecnologías que patentan en la producción de bienes finales. Entre ellas se encuentran los centros de investigación, las universidades, las oficinas de gobierno y los despachos de abogados.
} 
inventiva ( $c f$. tabla 2). Las ENP tienen el mayor número de reivindicaciones en promedio ${ }^{26}$ (17.2), lo mismo sucede con el promedio de sus citas forward $^{27}$ y el promedio de clases $^{28}$ y sus citas backward, además, el número de inventores promedio ${ }^{29}$ supera el promedio general. Esto indica que, si bien el peso de las ENP es pequeño, 3\% respecto del total, contribuyen con patentes novedosas y complejas.

Por su parte, las empresas presentan un conocimiento más diverso, con reivindicaciones promedio (15.2), citas (backward y forward) comparativamente bajas y un número de clases e inventores relativamente altos: 5.5 y 2.6, respectivamente ( $c f$. tabla 2). En el caso de las alianzas, se trata de un conocimiento fundamentalmente especializado y tienen el promedio de reivindicaciones (13.7) y de citas forward (3.5) entre los más bajos ${ }^{30}$. Del número de clases (5.2) por debajo del promedio, se puede señalar que la actividad inventiva de las alianzas se relaciona con pocos dominios, pero con un bagaje de conocimiento generado previamente muy alto (elevada citas backward, 74.6) y con el número más alto de inventores (3.3). Finalmente, en el caso de los inventores, el conocimiento previo que citan es bajo (15.4), así como sus reivindicaciones (13.5); los dominios en los que operan son relativamente poco numerosos ( 4.5 clases) y con un número de inventores bajo (1.3 inventores por patente). Se puede decir que el conocimiento generado por los inventores es relativamente simple. En resumen, el conocimiento de las ENP es novedoso y complejo, el de las empresas diverso, el de las alianzas especializado y el de los inventores independientes, relativamente simple. ( $c f$. tabla 2 ).

¿Cuál es el peso de cada uno de estos agentes en la producción de patentes? Los distintos tipos de agentes contribuyen de manera diferencial en la actividad inventiva. Solo 5 agentes (todos ellos empresas: Toyota, Honda, General Motors, Ford y Nissan) tienen más de 100 patentes, el resto producen menos de 50. De los 20 agentes con más patentes, 2 son alianzas ${ }^{31}$ (lo cual muestra la importancia de este tipo de organización) y 2 son empresas que no pertenecen al sector automotriz ${ }^{32}$.

En el caso de las empresas, la figura 3 representa las 10 principales empresas, periodo 19762012. En esta se puede observar el liderazgo de Honda en el periodo 2000-2007 y el de Toyota del 2008 en adelante. Asimismo, en los últimos 4 años, destaca el repunte de General Motors, explicada en gran medida por su alianza con otras empresas.

Si se examina con más detalle el periodo 1976-2012, se observa lo siguiente: un grupo pequeño de empresas (16 entre 1976 y 1982 y 19 de 1983 a 1988) patentan en estos 2 periodos iniciales.

\footnotetext{
${ }^{26}$ Las reivindicaciones muestran puntualmente los derechos de propiedad intelectual de los propietarios. El número de reivindicaciones da una idea de la novedad del conocimiento patentado.

27 Todas las patentes tienen referencias (citas) de otras patentes, de tal modo que se puede establecer una relación entre 2 patentes por medio de las citas. Dicha relación puede ser hacia adelante (forward) cuando la patente B es citada por la patente A, o hacia atrás (backward) si la patente B cita a la patente A. Así, cuando una patente cita a otras patentes (citas backward) significa que el conocimiento que reivindica tiene antecedentes en otras patentes. Mientras que una patente que es citada (citas forward) significa que su conocimiento ha sido el antecedente o fuente de conocimiento de otra patente.

${ }^{28}$ Una patente puede tener una o más clases (ver notas 11 y 15). Cuantas más clases tenga, a más dominios tecnológicos pertenece el conocimiento que reivindica y, por lo tanto, es más complejo.

${ }^{29}$ Las patentes indican los nombres y la cantidad de los inventores que participaron en el desarrollo del conocimiento patentado. El número de inventores promedio indica el tamaño medio de los equipos de investigación que generan una patente.

${ }^{30}$ La mayoría de las patentes en alianza tiene pocos años y, por lo tanto, son poco citadas.

${ }^{31}$ La primera es una especialización horizontal (Giannitsis y Kager, 2009) conocida como Global Hybrid Cooperation compuesta por BMW, Chrysler, Daimler y General Motors y la segunda es una especialización vertical integrada por Toyota y su subsidiaria Aisin.

32 Mattel, que es una empresa de la industria del juguete, e Invacare, especializado en diseñar sillas de ruedas.
} 


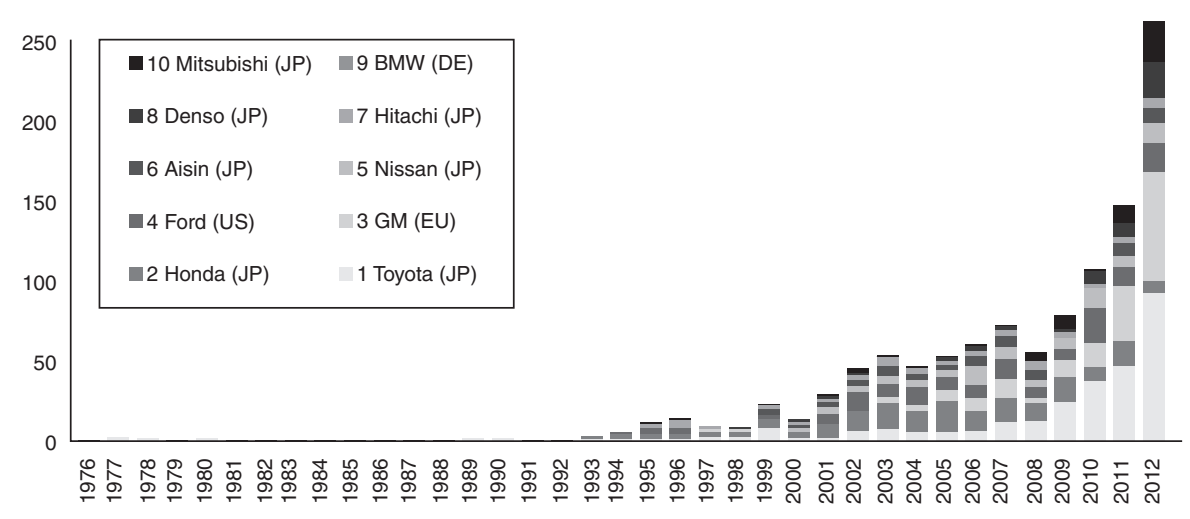

Figura 3. Patentes de las 10 principales empresas que patentan en VE (1976-2012).

Fuente: ibid.

Sin embargo, a partir de la década de 1990 crece esta población hasta llegar, en el último periodo (2006-2012), a 234 empresas. ¿Cómo evoluciona el liderazgo de la actividad inventiva? En los periodos iniciales (1976-1982 y 1983-1988) las empresas líderes fueron Lucas Industries y Peg Perego Pines $^{33}$, en el primer y segundo periodo, respectivamente. En ambos periodos la actividad inventiva de las empresas automotrices era muy baja. En los periodos subsecuentes emerge el liderazgo de las empresas japonesas Aisin (subsidiaria de Toyota), Honda y Toyota y, en menor medida, las empresas de origen estadounidense (GM, Ford) y europeo (BMW).

Por su parte, las alianzas se han convertido en un elemento clave de la actividad inventiva, por 2 razones: a) porque cooperando con otra empresa es posible producir conocimiento especializado y b) porque ante eventuales bloqueos, la alianza incrementa el poder de negociación. A lo largo de todo el periodo de estudio se construyeron 25 alianzas. Se destacan la alianza Global Hybrid Cooperation (conformada por BMW, Chrysler, Daimler y General Motors) con 33 patentes, Toyota que cuenta con 6 alianzas y General Motors que tiene 4 alianzas.

Desde el punto de vista de la evolución de las alianzas, se puede distinguir 3 momentos. Exceptuando la primera alianza - Toyota y Denso en 1977-, durante los primeros 19 años del periodo no se registra ninguna alianza. Durante la década siguiente — a partir de la alianza Toyota-Kanto en 1996- se crean una o 2 alianzas por año. Y a partir del 2007 el número de patentes resultado de una alianza crece explosivamente. En particular, durante 2011 y 2012, 11 alianzas registraron 66 patentes, lo que representa el $67.34 \%$ del total de patentes generadas en alianzas $^{34}$. Todo indica que en el futuro las alianzas se convertirán en un mecanismo para producir conocimiento especializado.

Por su parte, existen 35 ENP de las cuales, los centros de investigación privados aportan el mayor número de patentes: DEKA (un centro independiente) y Equos Reserch (centro de investigación de Toyota) con 14 y 12 patentes, respectivamente. Seguidas por un instituto público taiwanés Industriael Technology Research Institute y Paice ${ }^{35}$ un centro de investigación privado

\footnotetext{
33 Dedicada a la fabricación de productos para el cuidado infantil. Empresa que no pertenece al sector automotriz.

${ }^{34}$ Resalta el hecho de que Honda, a pesar de ser una de las empresas líderes en el sector, no se alía mucho. Solo tiene 2 patentes logradas en alianza, una con The Regents of University of California, en 2005 y otra con The UWM Research Foundation en 2012.

${ }^{35}$ Paice es un buen ejemplo del significado del valor de los derechos de propiedad intelectual en los vehículos eléctricos. Este centro de investigación demandó a Toyota por utilizar ilegalmente conocimiento patentado por Paice. Toyota estaba
} 

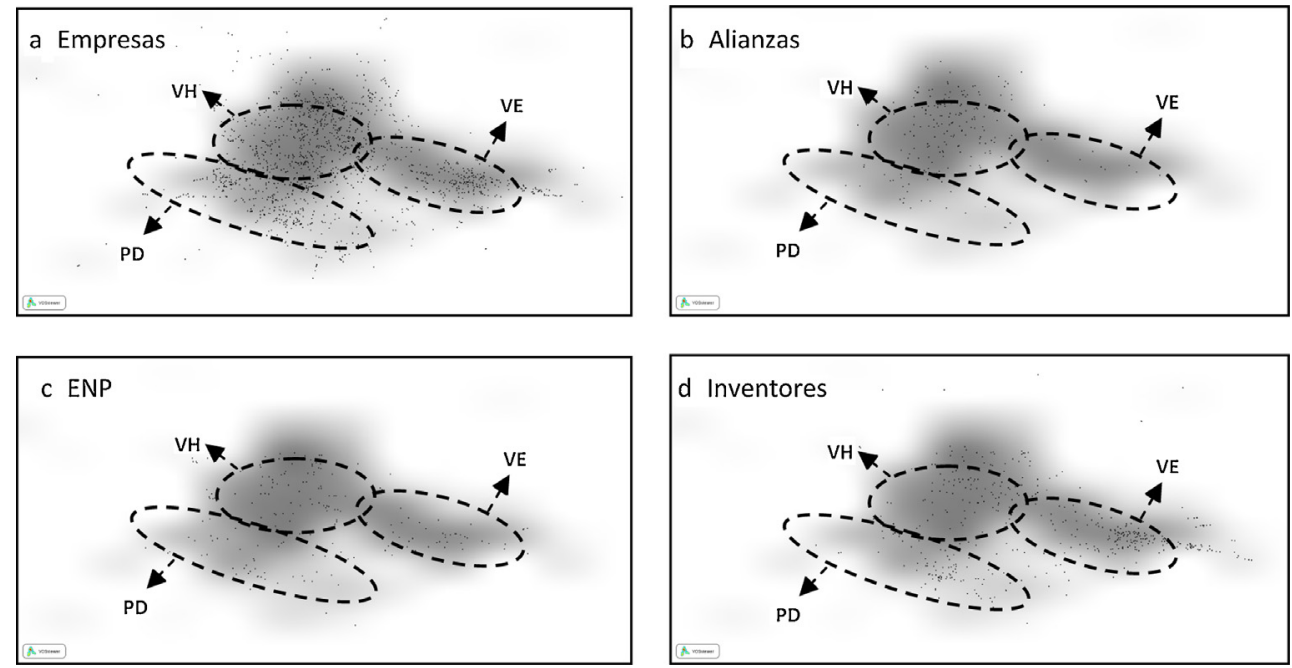

Figura 4. Distribución de los agentes en la red de clases de los VE (1976-2012).

PD: procesamiento de datos; VE: vehículos totalmente eléctricos; VH: vehículos híbridos.

Fuente: ibid.

(ambas con 4 patentes). El resto de las ENP tienen 3 o menos patentes. Como se señaló más arriba, las ENP son una fuente importante de conocimiento profundo ( $c f$. tabla 2), sin embargo, dependiendo de las estrategias que elijan (conceder licencias o no), pueden convertirse en una palanca o en un obstáculo para la innovación de los VE.

¿En qué clases tecnológicas se concentran estos tipos de agentes? En la figura 4 se observa la distribución de agentes en la red de clases tecnológicas. En el caso de las empresas ( $c f$. fig. 4a), su conocimiento cubre el $86.21 \%$ del total de clases. Si se le suman a Toyota todas las clases de sus subsidiarias y alianzas, esta alcanza a cubrir el 25.31. Nivel que refleja las limitaciones, aun del agente con mayores recursos del sector automotriz, de abarcar todas las clases tecnológicas.

En el caso de las alianzas ( $c f$. fig. 4b) su actividad inventiva se concentra en los espacios más densos de la red, donde hay más conocimiento desarrollado y, particularmente, en el área que corresponde a los vehículos híbridos. Este tipo de agente se vincula con 231 clases $(9.64 \%$ del total del sistema). Su importancia parece no radicar en el volumen de clases sino en la integración de conocimiento que realiza ${ }^{36}$. Por su parte, el conocimiento de las ENP ( $c f$. fig. 4c) no se encuentra extendido por toda la red ni tampoco en las áreas más densamente pobladas. La ENP aporta al sistema conocimiento en áreas poco exploradas, lo cual es consistente con su propia actividad de investigación, que se refleja en el alto número de sus citas forward ( $c f$. tabla 2). Es un agente pionero. Por último, el conocimiento de los inventores, al igual que las empresas, también se extiende a lo largo de la red, principalmente en las áreas más densas ( $c f$. fig. $4 \mathrm{~d})$, pero con cierto sesgo (17.09\% de sus clases) hacia los VE pequeños como sillas de ruedas o carros de golf.

infringiendo derechos de propiedad de Paice en su hybrid synergy drive system de sus vehículos Prius, Highlander y Lexus RX400h. La corte del Distrito de Texas determinó que Toyota debía pagar regalías a Paice del $0.48,0.32$ y $0.26 \%$ (de sus respectivos modelos) sobre el precio total de cada unidad vendida. Ver, Paice LLC v. Toyota Motor Corp., No. 2:04-CV-211-DF, 2006 WL 2385139 (E.D. Tex. Aug. 16, 2006).

36 Esto se discute con mayor profundidad más adelante. 


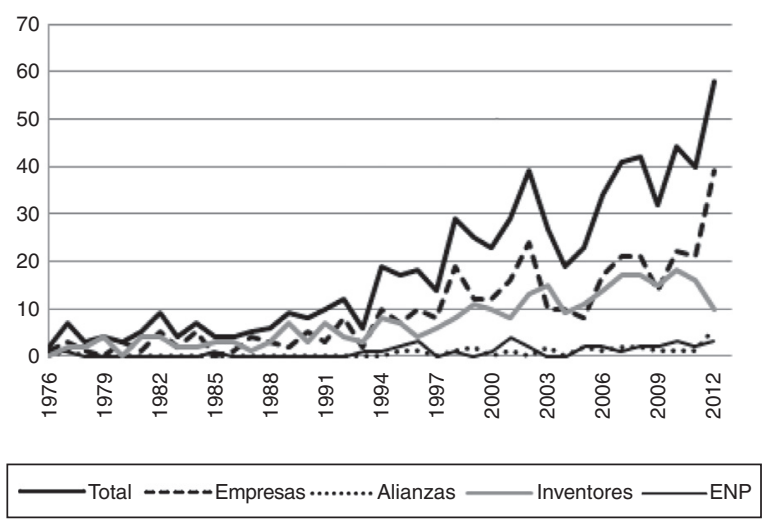

Figura 5. Nuevos agentes en VE (1976-2012).

Fuente: ibid.

En resumen, los 4 tipos de agentes identificados mantienen diferencias cualitativas y cuantitativas. Los datos promedio son importantes porque nos brindan una imagen general de la contribución de cada agente. Sin embargo, se requiere analizar más en profundidad para caracterizar mejor el conocimiento que aporta cada agente. Esto se examina en la siguiente sección.

\section{Evolución de los agentes y su conocimiento en la invención de los vehículos eléctricos}

¿Cómo ha evolucionado el conocimiento de los agentes en la actividad inventiva de los VE? La información sobre el ingreso de nuevos agentes y clases permitirá avanzar una parte de la respuesta. En la figura 5 se observa cómo en el periodo 1976-1991 crece el número de nuevos agentes $^{37}$. El número de nuevos agentes —entre empresas e inventores - aumenta ligeramente (de 2 a 10 agentes, alrededor de un nuevo agente cada 2 años). De 1992 en adelante, crece el número de nuevos agentes, principalmente las empresas ${ }^{38}$. En particular, en 2011 y 2012 ingresan sobre todo empresas y se crean nuevas alianzas ${ }^{39}$. Este incremento en el número de participantes nuevos se asocia con la expansión del espacio de exploración.

Desde el inicio del periodo de estudio y durante 15 años, relativamente pocas clases nuevas se incorporaron en el sector de los VE (cf. fig. 6). Sin embargo, a partir de la década de 1990, las nuevas clases crecen de manera exponencial. Con 3 picos máximos: a) en 2002 se integran 172 nuevas clases; b) 202 en 2011 y c) 270 en 2012. Esta expansión de nuevas clases tecnológicas obedece al hecho de que durante la década de 1990 empieza la competencia tecnológica y económica en el sector automotriz por diseñar y desarrollar VE. Esta competencia presiona a las empresas a mejorar y a construir sistemas complejos anidados. Como resultado, para validar institucionalmente los nuevos espacios de exploración, las oficinas de patentes se ven obligadas a crear nuevas clases tecnológicas.

\footnotetext{
37 Se contabilizan como nuevos agentes aquellos agentes que nunca antes patentaron en el periodo bajo estudio.

38 Aunque de 2002 a 2004 disminuye el ingreso de nuevos agentes, de todas maneras la tendencia secular al incremento de nuevos agentes se mantiene.

39 En tanto que disminuye el ingreso de nuevos inventores. Durante el periodo 1976-2012, a las alianzas y a las ENP ingresan aproximadamente un agente nuevo por año (0.96 nuevas alianzas y 1.28 nuevas ENP).
} 


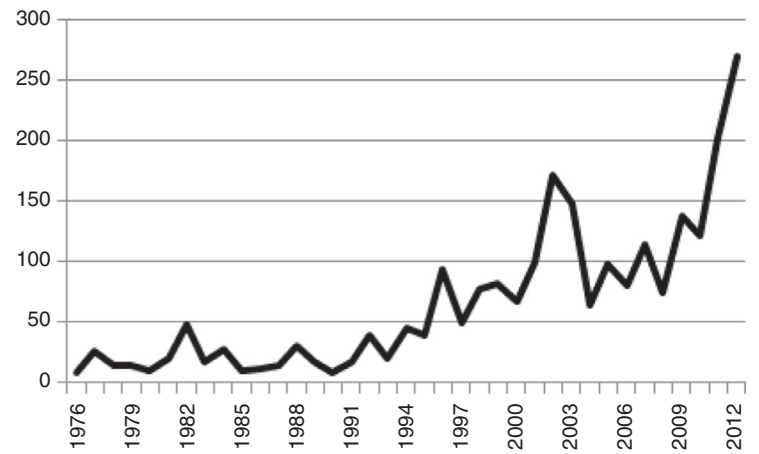

Figura 6. Nuevas clases en VE (1976-2012).

Fuente: ibid.

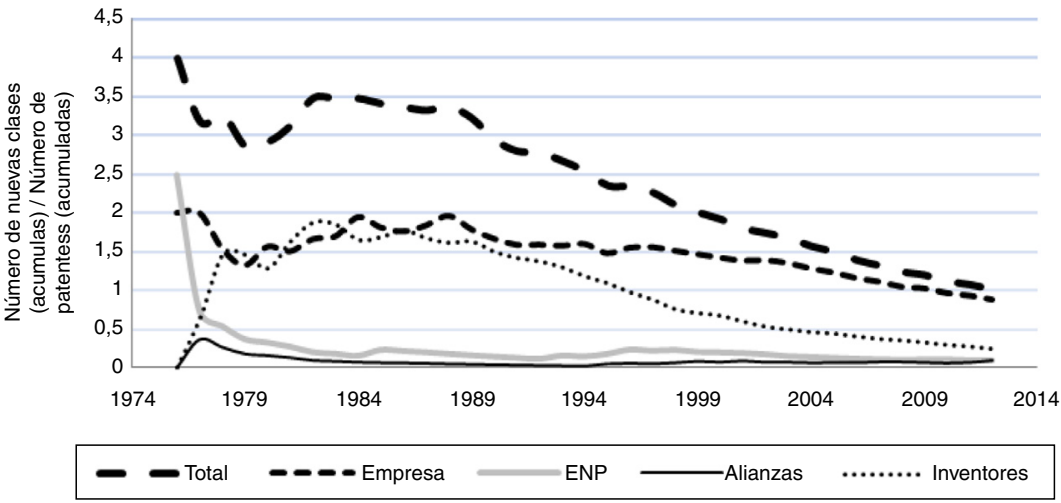

Figura 7. Intensidad de exploración de nuevas clases en los VE (1976-2012).

Fuente: ibid.

Cabe preguntarse si existen diferencias en la intensidad de la exploración de nuevas clases por cada uno de los tipos de agentes. Con este propósito se construye un indicador que representa la intensidad con la cual los agentes exploran nuevas clases ${ }^{40}$ (cf. fig. 7). En los primeros años (19761979), la búsqueda de novedad, aunque distribuida, es más intensa en las empresas y los inventores. Durante la década de 1980 la intensidad de la búsqueda de novedad se mantiene relativamente constante para las alianzas y las ENP (a tasas de 0.08 y 0.2 , respectivamente en promedio), y más intensa en el caso de las empresas y los investigadores (1.75 y 1.66 , respectivamente en promedio). Sin embargo, durante de la década de 1990 disminuye la intensidad de búsqueda de nuevas clases, especialmente de los inventores (de 1.49 en 1990 a 0.23 en 2012) y de las empresas (de 1.66 en 1990 a 0.87 en 2012). En este mismo periodo, en el caso de las alianzas, esta tasa es casi nula, y pequeña en el caso de la ENP. En resumen, durante el periodo se explora en nuevas clases, pero la intensidad en dicha exploración, en general, se reduce. Esto implica que la actividad inventiva tiende más a recombinar clases tecnológicas con las que se ha patentado en el pasado y en, consecuencia, la búsqueda en un espacio más acotado conduce a la emergencia de áreas de investigación redundantes o traslapadas (fig. 7).

\footnotetext{
$\overline{40}$ Esto es, el cociente entre el número de las nuevas clases acumuladas y el número de patentes acumuladas por cada tipo de agente.
} 


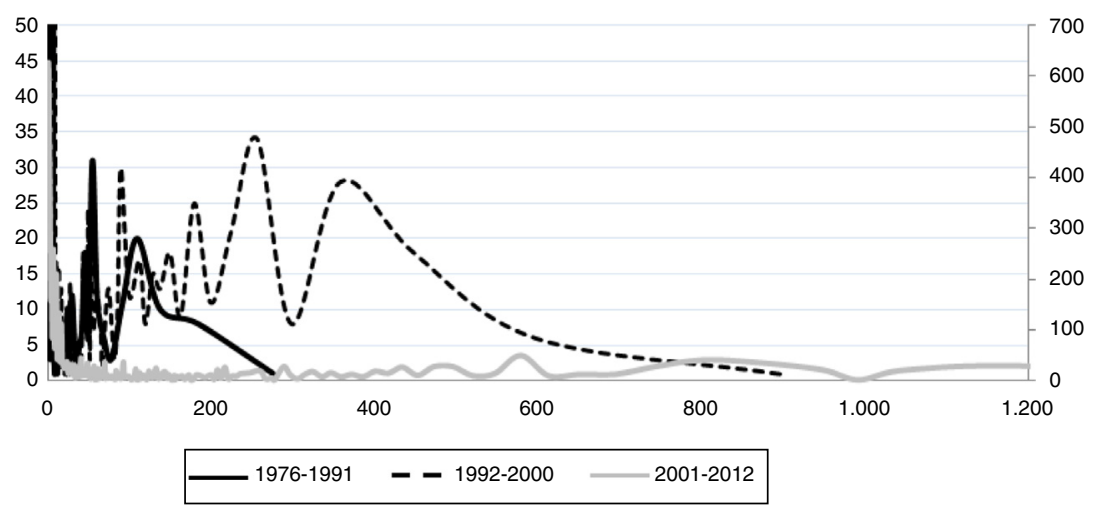

Figura 8. Distribución de los índices de concentración de los VE por periodos.

La escala de los 2 primeros periodos se encuentra a la izquierda y la escala del último periodo a la derecha.

Fuente: ibid.

Cabe preguntarse ¿cómo distinguir si el espacio de búsqueda de los agentes se encuentra, desde el punto de vista de las clases tecnológicas, concentrado o diversificado? Por ello se calculan coeficientes de concentración para los periodos 1976-1991, 1992-2000 y 2001-201241 (cf. fig. 8). Si la actividad inventiva estuviera especializada se observaría una distribución normal de probabilidad con una varianza baja; en el límite se representaría como una línea vertical. Si la actividad inventiva fuera diversa la distribución de probabilidad sería de una forma normal con una varianza grande; en el límite se representaría como una línea horizontal.

De la figura 8 se puede señalar lo siguiente: los resultados del sistema de invención de los VE para los 3 periodos seleccionados presentan una distribución de probabilidad de tipo «ley de potencia» que se acentúa conforme pasa el tiempo ( $c f$. fig. 8). Esto significa que el patrón de búsqueda de los agentes se está concentrando en grupos específicos de clases tecnológicas donde coexiste la especialización y la diversificación.

A este respecto conviene analizar cómo, en la medida en que participan en la actividad inventiva, los agentes aportan conocimiento al sistema. Por ello, es necesario representar la especificación de una patente y la profundidad de su conocimiento ${ }^{42}$. La figura 9 refleja la evolución por periodos del producto del número promedio de las clases multiplicado por el promedio de su profundidad para cada tipo de agente. En el primer periodo (1976-1982) se observa que el tipo de conocimiento de todos los agentes, salvo las ENP, según su nivel de especificación y profundidad, es similar. En los siguientes 2 periodos (1983-1988 y 1989-1994) tanto las empresas como las ENP proporcionaron

\footnotetext{
${ }^{41}$ Para identificar los patrones de búsqueda concentrado y diversificado se siguieron los siguientes pasos: a) se calcula el coeficiente de concentración para todos los agentes respecto a las clases, en este caso se mide la proporción que representa una clase particular para un agente específico entre la proporción que esa misma clase representa en toda la industria para los periodos elegidos; b) se ordenan los índices de concentración para obtener rangos homogéneos y se convierten en números naturales y c) se calcula la frecuencia de estos valores y se grafica.

${ }^{42}$ Indicador de especificación de una patente: las patentes pueden ser descritas de acuerdo al número de clases tecnológicas. Una cadena corta hace referencia a un conocimiento general. Una cadena larga a un conocimiento específico. El número de clases (la longitud de una cadena) que describe una patente da cuenta de su especificación.

Indicador de profundidad de una patente: para el caso de los vehículos eléctricos, la USPTO agrupa sus diferentes clases hasta 8 niveles de profundidad de forma jerárquica: línea principal (mainline), nivel 1, nivel 2, nivel 3, nivel 4, nivel 5, nivel 6 y nivel 7. Una clase de nivel 4 pertenece a una clase de nivel 3, esta a su vez a una clase de nivel 2, y así sucesivamente. De este modo se puede examinar la profundidad del conocimiento de una patente.
} 


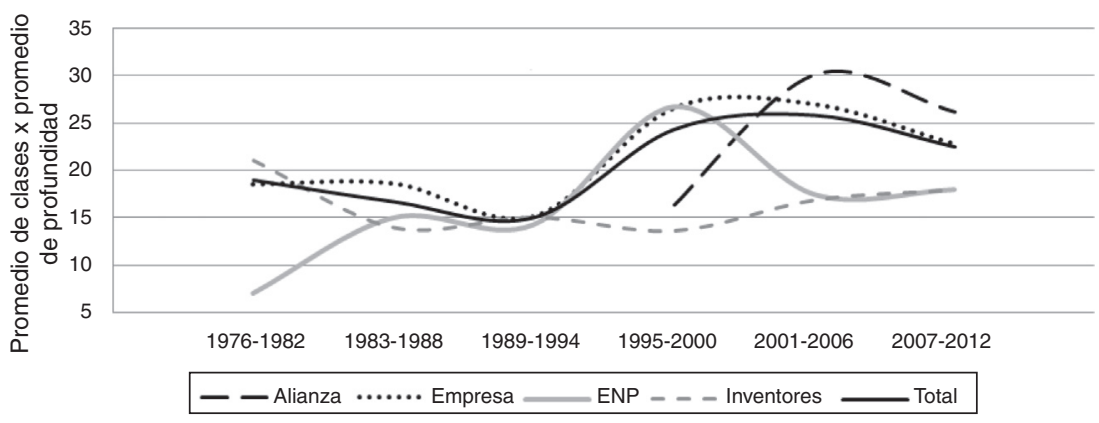

Figura 9. Evolución de la combinación promedio de las clases y profundidad en los VE por periodos (1976-2012). Fuente: ibid.

al sistema el conocimiento más profundo y específico. Como se señaló más arriba, la contribución de las ENP no radica tanto en el número como en la calidad de sus patentes, toda vez que cuenta con el más alto nivel promedio de citas forward y reivindicaciones ( $c f$. tabla 2). En el periodo 1995-2000 fueron las empresas y en el 2001-2006 las alianzas las que contribuyeron con el conocimiento más especializado y profundo al sistema. En el periodo 2007-2012, después de alcanzar un máximo, desciende la contribución de las empresas y de las alianzas, pero estas últimas son las que más aportan. En todos los periodos, exceptuando el primero, los inventores individuales aportan relativamente poco conocimiento.

Para enriquecer esta descripción la tabla 3

muestra la frecuencia de clases y su profundidad para cada tipo de agente ${ }^{43}$. Las alianzas tienen un rango de especificación que va de 1 a 31 clases (un rango alto) aunque todas sus modas son relativamente bajas ${ }^{44}$. Por su parte, las empresas tienen los grados más altos de especificación (35 clases) y profundidad (nivel 8$)^{45}$. La moda de la especificación para este tipo de agente es relativamente alta ( 5 clases) pero la profundidad se concentra en 2 . Así, las empresas son un tipo de agente que aporta al sistema las cadenas más largas y profundas de conocimiento.

Las ENP, a su vez, muestran un grado de especificación que varía entre 2 y 15 clases. Es un agente con un nivel de especificación alto (moda de 6 clases) y un nivel de profundidad similar al resto de los agentes (moda de 2). Finalmente, los inventores aportan conocimiento diverso al sistema: tienen los niveles más bajos de especificación (la moda de sus clases es 3) y baja profundidad (moda de 2). En resumen, las alianzas y las ENP aportan conocimiento específico y profundo al sistema. Las empresas contribuyen con conocimiento diverso en especificidad y profundidad. Y, finalmente, los inventores aportan conocimiento diverso, pero relativamente poco especializado y poco profundo.

A continuación, cabe preguntar cómo, desde el punto de vista de los agentes, se concentra el conocimiento contenido en las patentes. ¿El conocimiento se encuentra disperso o concentrado?

\footnotetext{
${ }^{43}$ La tabla 3 se construyó de la manera siguiente. Las filas especifican la longitud de clases y las columnas la profundidad según el tipo de agente. ¿Cómo se interpreta la tabla? Los cuadros resaltados en gris medio son la moda (mayor frecuencia) de la combinación de clases y profundidad. Por ejemplo, en el primer recuadro (alianzas) se resalta en color gris medio el número 25. Esto significa que 25 patentes de las alianzas tienen 3 clases y un nivel 2 de profundidad. Los cuadros en gris claro señalan la moda de la longitud de las clases y de la profundidad para cada tipo de agente. Los cuadros en negro identifican el máximo grado de profundidad o especificación utilizados por los agentes.

44 Es probable que esto se asocie al hecho de que las alianzas son un fenómeno relativamente reciente (1995 en adelante) (cf. fig. 9).

45 De hecho, la patente 7969039, otorgada a Honda en 2011, es la que tiene estas 2 características.
} 
Tabla 3

Frecuencia de clases según nivel de especialización y profundidad para cada tipo de agente en VE (1976-2012)

\begin{tabular}{|c|c|c|c|c|c|c|c|c|}
\hline \multirow[t]{2}{*}{ Agente/profundidad } & \multicolumn{8}{|c|}{ Número de clases } \\
\hline & 1 & 2 & 3 & 4 & 5 & 6 & 7 & 8 \\
\hline Alianza & 8 & 28 & 72 & 48 & 50 & 30 & 35 & 40 \\
\hline 1 & & & 3 & 3 & 2 & & 7 & 4 \\
\hline 2 & 8 & 14 & 25 & 23 & 18 & 10 & 14 & 15 \\
\hline 3 & & 10 & 23 & 11 & 13 & 9 & 7 & 8 \\
\hline 4 & & 4 & 14 & 6 & 11 & 6 & 2 & 3 \\
\hline 5 & & & 7 & 4 & 5 & 3 & 5 & 7 \\
\hline 6 & & & & 1 & 1 & 2 & & 2 \\
\hline 7 & & & & & & & & 1 \\
\hline Empresa & 46 & 466 & 1,023 & 1,220 & 1,240 & 1,074 & 805 & 680 \\
\hline 1 & & 21 & 103 & 149 & 137 & 119 & 90 & 70 \\
\hline 2 & 46 & 292 & 464 & 521 & 478 & 365 & 283 & 216 \\
\hline 3 & & 95 & 240 & 258 & 287 & 285 & 201 & 183 \\
\hline 4 & & 29 & 129 & 160 & 167 & 147 & 99 & 91 \\
\hline 5 & & 20 & 71 & 102 & 127 & 132 & 103 & 94 \\
\hline 6 & & 9 & 15 & 25 & 40 & 23 & 29 & 26 \\
\hline 7 & & & & 5 & 2 & 3 & & \\
\hline 8 & & & 1 & & 2 & & & \\
\hline$E N P$ & & 10 & 42 & 56 & 50 & 66 & 42 & 40 \\
\hline 1 & & & 9 & 4 & 15 & 4 & 11 & 8 \\
\hline 2 & & 5 & 16 & 24 & 10 & 20 & 15 & 11 \\
\hline 3 & & 3 & 9 & 17 & 12 & 19 & 8 & 9 \\
\hline 4 & & & 5 & 6 & 8 & 9 & 5 & 4 \\
\hline 5 & & 2 & 3 & 5 & 4 & 11 & 2 & 6 \\
\hline 6 & & & & & 1 & 3 & 1 & 1 \\
\hline 7 & & & & & & & & 1 \\
\hline Inventores & 3 & 80 & 249 & 292 & 205 & 138 & 154 & 104 \\
\hline 1 & & 10 & 40 & 49 & 34 & 19 & 32 & 14 \\
\hline 2 & 3 & 42 & 128 & 113 & 83 & 50 & 51 & 33 \\
\hline 3 & & 22 & 41 & 59 & 45 & 25 & 23 & 23 \\
\hline 4 & & 5 & 32 & 42 & 31 & 24 & 34 & 20 \\
\hline 5 & & 1 & 6 & 20 & 11 & 18 & 12 & 9 \\
\hline 6 & & & 2 & 8 & 1 & 2 & 2 & 5 \\
\hline 7 & & & & 1 & & & & \\
\hline
\end{tabular}

Agente/profundidad

Número de clases

\begin{tabular}{|c|c|c|c|c|c|c|c|c|c|c|c|c|}
\hline & 9 & 10 & 11 & 12 & 13 & 14 & 15 & 16 & 17 & 18 & 19 & 20 \\
\hline Alianza & 9 & 30 & 44 & & 13 & 28 & 30 & & 17 & & & \\
\hline 1 & & 4 & 3 & & 2 & 3 & 4 & & 3 & & & \\
\hline 2 & 6 & 6 & 10 & & 4 & 9 & 7 & & 6 & & & \\
\hline 3 & 1 & 13 & 13 & & 5 & 7 & 8 & & 3 & & & \\
\hline 4 & 2 & 4 & 13 & & 2 & 7 & 4 & & 2 & & & \\
\hline 5 & & 2 & 5 & & & 2 & 6 & & 1 & & & \\
\hline 6 & & & & & & & 1 & & & & & \\
\hline 7 & & 1 & & & & & & & 2 & & & \\
\hline Empresa & 657 & 530 & 583 & 432 & 286 & 280 & 195 & 96 & 136 & 72 & 133 & 100 \\
\hline 1 & 67 & 56 & 57 & 43 & 32 & 17 & 24 & 9 & 13 & 6 & 11 & 11 \\
\hline 2 & 202 & 149 & 179 & 129 & 83 & 73 & 67 & 34 & 27 & 18 & 45 & 30 \\
\hline
\end{tabular}


Tabla 3

(Continuación)

\begin{tabular}{|c|c|c|c|c|c|c|c|c|c|c|c|c|}
\hline \multirow[t]{2}{*}{ Agente/profundidad } & \multicolumn{12}{|c|}{ Número de clases } \\
\hline & 9 & 10 & 11 & 12 & 13 & 14 & 15 & 16 & 17 & 18 & 19 & 20 \\
\hline 3 & 157 & 127 & 174 & 118 & 70 & 74 & 48 & 24 & 39 & 20 & 36 & 22 \\
\hline 4 & 114 & 83 & 80 & 74 & 43 & 46 & 25 & 14 & 25 & 9 & 17 & 15 \\
\hline 5 & 85 & 84 & 70 & 48 & 40 & 49 & 24 & 9 & 25 & 12 & 18 & 20 \\
\hline 6 & 30 & 31 & 21 & 20 & 18 & 17 & 7 & 6 & 5 & 7 & 5 & 2 \\
\hline 7 & 1 & & 1 & & & 4 & & & 2 & & 1 & \\
\hline 8 & 1 & & 1 & & & & & & & & & \\
\hline$E N P$ & 54 & 30 & 33 & & & & 15 & & & & & \\
\hline 1 & 12 & 4 & 4 & & & & & & & & & \\
\hline 2 & 15 & 7 & 8 & & & & 2 & & & & & \\
\hline 3 & 17 & 11 & 9 & & & & 5 & & & & & \\
\hline 4 & 5 & 4 & 3 & & & & 2 & & & & & \\
\hline 5 & 4 & 2 & 8 & & & & 5 & & & & & \\
\hline 6 & 1 & 2 & 1 & & & & 1 & & & & & \\
\hline \multicolumn{13}{|l|}{7} \\
\hline Inventores & 45 & 30 & 33 & 12 & 26 & & 15 & 48 & 17 & & & \\
\hline 1 & 5 & 6 & 3 & 3 & 2 & & 2 & 11 & 1 & & & \\
\hline 2 & 11 & 8 & 7 & 7 & 2 & & 2 & 15 & 3 & & & \\
\hline 3 & 10 & 9 & 7 & 1 & 9 & & 3 & 9 & 3 & & & \\
\hline 4 & 14 & 5 & 11 & 1 & 4 & & 3 & 10 & 3 & & & \\
\hline 5 & 3 & 1 & 4 & & 8 & & 4 & 3 & 4 & & & \\
\hline 6 & 2 & 1 & 1 & & 1 & & 1 & & 2 & & & \\
\hline 7 & & & & & & & & & 1 & & & \\
\hline
\end{tabular}

Agente/profundidad

Número de clases

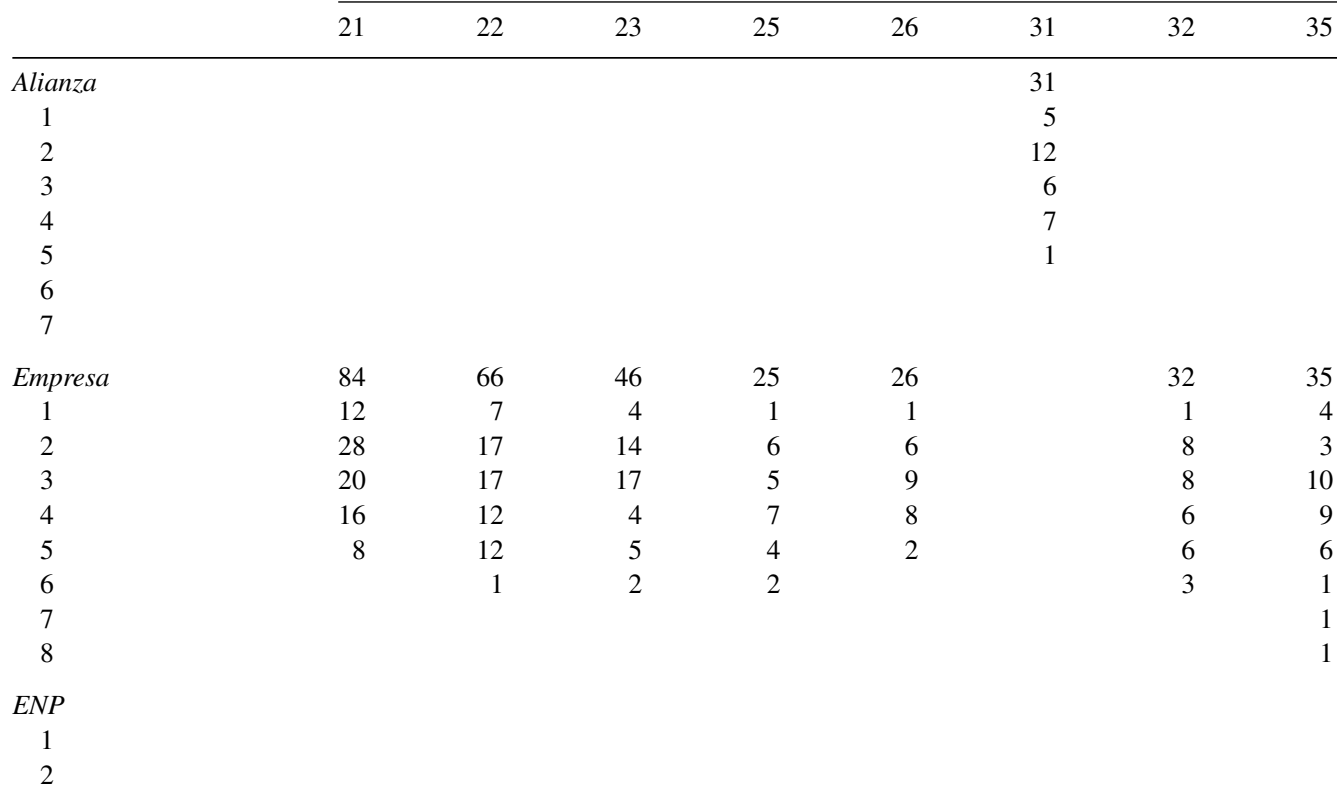


Tabla 3

(Continuación)

\begin{tabular}{|c|c|c|c|c|c|c|c|c|}
\hline \multirow[t]{2}{*}{ Agente/profundidad } & \multicolumn{8}{|c|}{ Número de clases } \\
\hline & 21 & 22 & 23 & 25 & 26 & 31 & 32 & 35 \\
\hline \multicolumn{9}{|l|}{3} \\
\hline \multicolumn{9}{|l|}{4} \\
\hline \multicolumn{9}{|l|}{5} \\
\hline \multicolumn{9}{|l|}{6} \\
\hline \multicolumn{9}{|l|}{7} \\
\hline \multicolumn{9}{|l|}{ Inventores } \\
\hline \multicolumn{9}{|l|}{1} \\
\hline \multicolumn{9}{|l|}{2} \\
\hline \multicolumn{9}{|l|}{3} \\
\hline \multicolumn{9}{|l|}{4} \\
\hline \multicolumn{9}{|l|}{5} \\
\hline \multicolumn{9}{|l|}{6} \\
\hline 7 & & & & & & & & \\
\hline
\end{tabular}

Fuente: ibid.

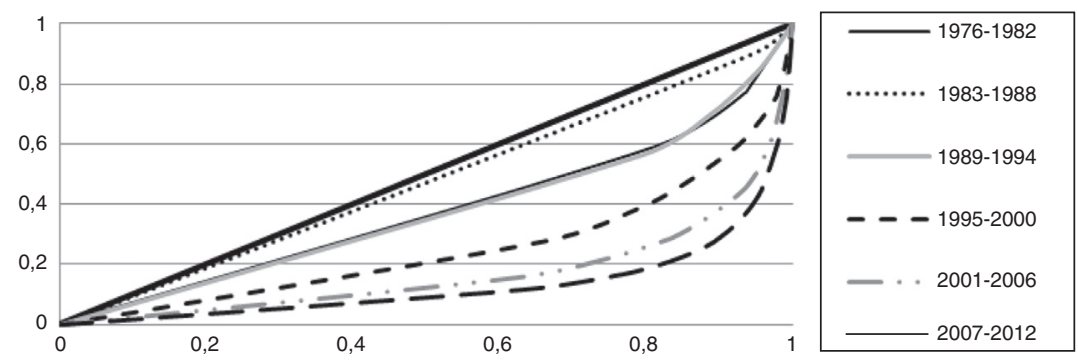

Figura 10. Curvas de Lorenz para VE. Subperiodos de 1976 a 2012.

Fuente: ibid.

Es posible encontrar la respuesta en la forma en la que evolucionan las curvas de Lorenz para el periodo 1976-2012 (cf. fig. 10) ${ }^{46}$. El primer periodo (1976-1982) tiene una curva medianamente distribuida, el conocimiento está poco concentrado, en tanto que la curva del periodo 1983-1988 es más recta, el conocimiento está más distribuido ${ }^{47}$. Es a partir del tercer periodo (1989-1994) en adelante, cuando las curvas de Lorenz tienden a alejarse de la diagonal principal. Es decir, a partir del tercer periodo un pequeño grupo de agentes concentra un mayor número de patentes.

Esto quiere decir que, en la actividad inventiva relacionada con los VE, ingresan agentes y se crean nuevas áreas de investigación (ver figs. 5 y 6), pero el grado de concentración de la actividad inventiva es cada vez mayor. ¿Cómo se explican estos niveles crecientes de concentración? Una razón plausible de este comportamiento radica en la complejidad del diseño y desarrollo de los VE. Solo aquellos agentes con experiencia acumulada, capacidades y recursos significativos tienen mayor probabilidad de resolver problemas complejos. Esta tendencia a la concentración se ve

\footnotetext{
46 En nuestro caso, la curva de Lorenz muestra el nivel de concentración de las patentes por agente. Una distribución uniforme de las patentes describiría una línea diagonal completamente recta. Cuanto más se aleje la curva de esta línea recta más concentradas se encuentran las patentes en pocos agentes.

${ }^{47}$ Lo cual puede asociarse a que es periodo con poca actividad inventiva.
} 

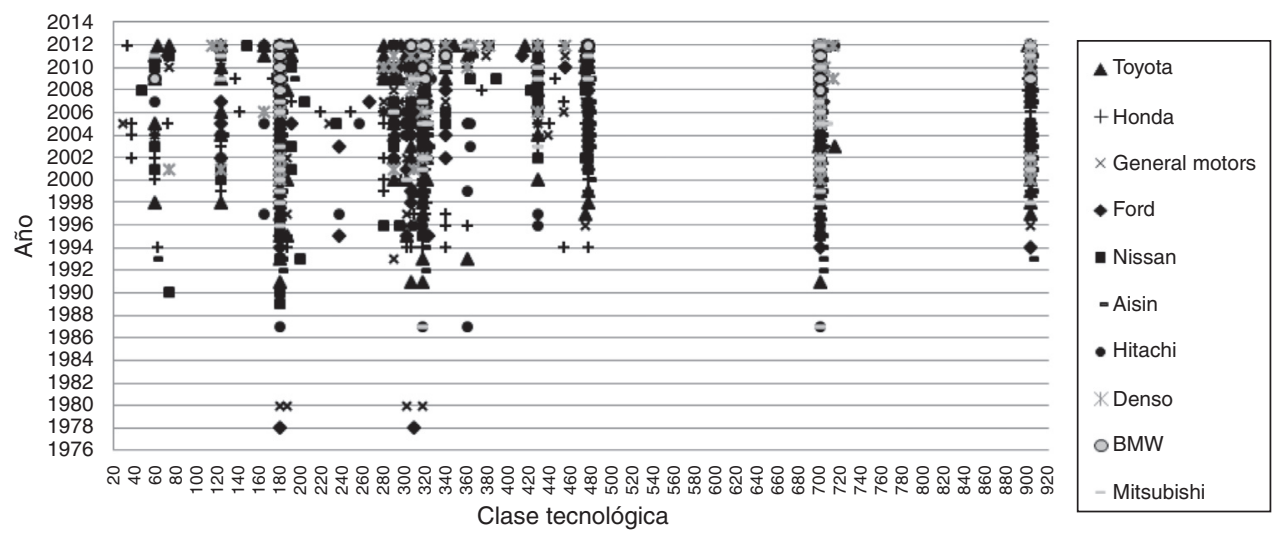

Figura 11. Clases en las que patentan las 10 principales empresas en VE (1976-2012).

Fuente: ibid.

atenuada toda vez que en el diseño y desarrollo de los VE emergen problemas que requieren crear nuevos dominios tecnológicos. En el diseño de los VE no existe un diseño dominante. La tecnología se encuentra en un estado fluido, situación que abre oportunidades para que nuevos agentes ingresen en el sector. Esto explica en parte la coexistencia de la actividad inventiva cada vez más concentrada con el ingreso de nuevos agentes.

Desde esta perspectiva interesa examinar la evolución de las clases en las que patentan las 10 principales empresas ( $c f$. fig. 11). Esta información permite representar la evolución del patrón de búsqueda de las empresas. Se observa que desde 1976 hasta fines de la década de 1980 las empresas patentan en un grupo pequeño de clases tecnológicas relacionadas con el motor eléctrico, la batería, la conducción de energía y elementos mecánicos. Sin embargo, en la década de 1990 en adelante, el número de clases en las que están concentradas las empresas se expande. En particular, durante la década de 1990 y la primera mitad de la década del 2000, las empresas se concentran en el motor eléctrico; en el desarrollo de vehículos híbridos; los sistemas de acumulación de energía ${ }^{48}$; en sistemas de procesamiento de datos —asociado al crecimiento de la electrónica y cómputo en los vehículos ${ }^{49}$ - y en el sistema de frenado regenerativo propio de los VE. Finalmente, desde mediados de la década de 2000 hasta el 2012, a las clases tecnológicas del periodo anterior se añaden nuevas clases: desarrollo de sistemas de interconexión electrónica, de cómputo y comunicación del vehículo, así como los sistemas de control y administración de energía. La emergencia de estas clases da cuenta de un cambio cualitativo profundo de la actividad inventiva: el patrón de búsqueda migra de las clases tecnológicas de naturaleza tangible (motor, batería) a clases de naturaleza intangible (software).

La figura 11 muestra áreas exploradas por uno o varios agentes y áreas vacías. Toyota es una empresa que se relaciona con un gran número de clases. Y, en la medida en que Denso y Aisin son empresas subsidiarias de Toyota, se puede señalar que Toyota patenta en una buena parte de las clases que corresponden al espectro de los VE (25.35\% de las clases). Combina sus capacidades de búsqueda con la especialización en pocas clases de Denso y con la diversidad de clases de Aisin. Honda está presente en una diversidad amplia y, en algunos casos, especializada de clases

\footnotetext{
${ }^{48}$ El diseño y desarrollo de baterías avanzadas son claves en este periodo (Lara y Salazar, 2013, Reyes, 2012).

49 Bauer, 2007, Juliussen y Robinson, 2010 y Lara, 2014.
} 


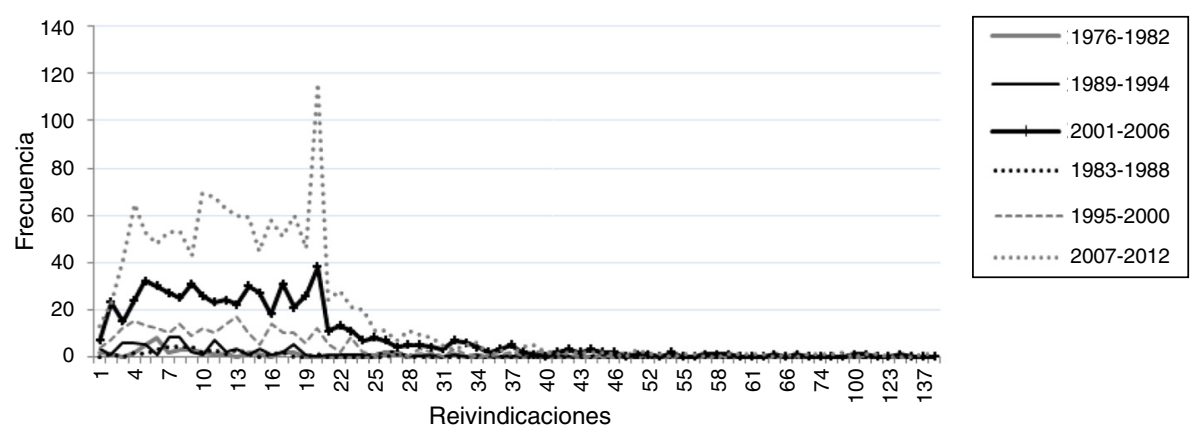

Figura 12. Frecuencia de reivindicaciones para VE por periodos (1976-2012).

Fuente: ibid.

tecnológicas. Explora en áreas comunes a Toyota, pero también en áreas en las que Toyota está ausente. Si se compara en conjunto a General Motors y Ford con Toyota, las primeras están presentes en un número de clases tecnológicas más reducido $(20.71 \%$ de las clases, considerando sus alianzas y subsidiarias). Nissan, aunque cuenta con menos patentes, también es capaz de explorar un grupo relativamente diverso de clases, con especialización en algunas de ellas. Por su parte, Hitachi y Mitsubishi se encuentran más especializadas en los principales dominios con algunas patentes en áreas poco exploradas. Finalmente BMW, gracias a sus alianzas de los últimos años, logra posicionarse en la lista de las 10 empresas con mayor actividad inventiva en los VE, sin embargo, se especializa en dominios tradicionales ( $c f$. fig. 11). De esta manera, dados los recursos (materiales y cognitivos) limitados no existe empresa capaz de explorar el conjunto de clases tecnológicas asociadas a los VE. En ese sentido se crean relaciones de competencia y cooperación tecnológica entre las empresas.

Entendemos que el espacio de la rivalidad o complementariedad depende de la manera en la que los agentes construyen, acumulan y se apropian del conocimiento tecnológico, bajo la forma de patentes. El problema surge cuando para explotar comercialmente una tecnología se requiere ensamblar una variedad de patentes. Determinar la posible existencia de las patentes traslapadas es objeto del análisis de la siguiente sección.

\section{La evolución de las patentes traslapadas en los vehículos eléctricos}

Se han desarrollado distintas técnicas para identificar las patentes traslapadas (IPO, 2011; Von Graevenitz et al., 2011; Hall et al., 2013), algunas de ellas (curvas de Lorenz y los índices de concentración) se examinaron más arriba. Para profundizar el análisis se incluyen en al análisis 3 indicadores: la frecuencia de reivindicaciones, la frecuencia de citas forward y la de citas backward.

Las reivindicaciones determinan los derechos de propiedad intelectual. Cuantas más reivindicaciones tenga un propietario de una patente, mayor será su derecho a excluir a otros de una área tecnológica ${ }^{50}$. La figura 12 muestra las distribuciones de frecuencia de las reivindicaciones para

\footnotetext{
$\overline{50}$ Una forma de medir es combinando el número de reivindicaciones y el número de patentes por medio de la distribución de frecuencias. Cuando la frecuencia toma la forma de una campana plana, se puede considerar que es baja la probabilidad de patentes traslapadas. La probabilidad de patentes traslapadas se incrementa cuanto más altas sean las frecuencias y cuando su distribución toma la forma de una sola cola (IPO, 2011).
} 

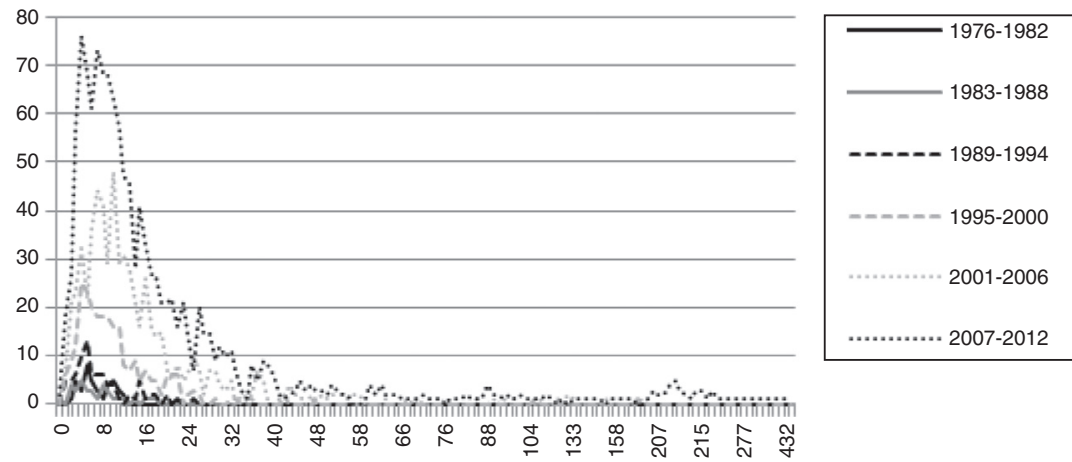

Figura 13. Frecuencia de citas backward para VE por periodos (1976-2012).

Fuente: ibid.

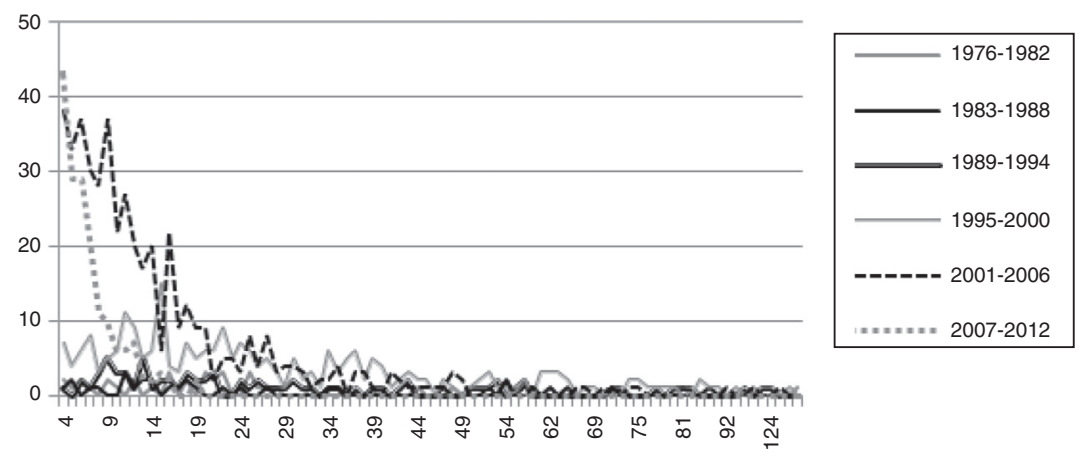

Figura 14. Frecuencia de citas forward para VE por periodos (1976-2012).

Fuente: ibid.

6 periodos. En el primer y segundo periodos sus curvas son relativamente planas: indican la baja probabilidad de patentes traslapadas. Sin embargo, en los 4 periodos siguientes, las frecuencias de reivindicaciones de las patentes crecen, y su distribución tiende a una sola cola, lo cual indica una mayor probabilidad de patentes traslapadas.

Otro indicador de la existencia de patentes traslapadas es la distribución de la frecuencia de citas forward y backward ${ }^{51}$. Cuando la moda de las citas backward se aleja del origen verticalmente significa que las patentes se citan más y, por lo tanto, se incrementa la posibilidad de la presencia de patentes traslapadas. Lo mismo sucede para las citas forward, pero la lectura es distinta: cuanto más alejada se encuentre verticalmente la moda, más citadas son las patentes. En la figura 13 se observa la distribución de frecuencia para los VE de las citas backward y en la figura 14 la distribución de frecuencia de las citas forward.

Respecto a las citas backward ( $c f$. fig. 13) en los 3 primeros periodos se observa un nivel bajo tanto del volumen como de la frecuencia de citas. Sin embargo, en el cuarto periodo (1995-2000) aunque la moda no se altera significativamente, el lado derecho de la curva se aleja del origen, lo que significa que un conjunto de patentes nuevas tiene un mayor número de citas backward. De 2001 al

\footnotetext{
$51 \mathrm{Su}$ interpretación es relativamente similar a la frecuencia de reivindicaciones. Se define ambas clases de citas en la nota a pie número 27 .
} 
2006, este fenómeno se repite; sin embargo la moda y la curva se desplazan más a la derecha. En el periodo 2006-2012 se presenta un fenómeno contradictorio: por un lado, la moda se desplaza a la izquierda y, por otro, la parte izquierda de la curva toma la forma bimodal. Esto se puede explicar como resultado de 2 factores: 1) la creación de nuevas clases tecnológicas (diversificación) ${ }^{52}$ y 2) la producción de un número significativo de patentes complejas y especializadas por parte de las alianzas, patentes con un número elevado de citas backward.

Vemos que en los 3 primeros periodos las curvas de las citas forward ${ }^{53}$ tienen una forma relativamente plana y con un bajo nivel de citas. En cambio, durante el periodo 1995-2000 un conjunto heterogéneo de patentes son citadas. Las patentes de este periodo se convierten en bloques de construcción útiles para acelerar la actividad inventiva en los siguientes periodos. El periodo 2001-2006 muestra una moda más cercana al origen, pero el lado derecho de su curva se desplaza a la izquierda. Lo que puede explicarse por la novedad de áreas de conocimiento exploradas y la especialización de la actividad inventiva del periodo siguiente. Y finalmente, el último periodo (2007-2012) no presenta un patrón claro debido a su reciente formación. Si exceptuamos este último periodo, las citas backward ayudan a representar la compleja red de interdependencia de las patentes, lo que indicaría que durante el periodo 1976-2012 ha crecido la probabilidad de la existencia de patentes traslapadas.

\section{Conclusiones}

En este punto se puede sintetizar cómo cambia en el tiempo la relación de las patentes traslapadas y la diversidad de agentes en la actividad inventiva de los VE. El primer hecho estilizado que es necesario destacar es que, como resultado de la actividad inventiva, se ha creado una red de conocimiento cada vez más compleja que crea las condiciones para la generación de patentes traslapadas.

En un primer periodo, 1976-1991, la red de conocimientos es incipiente y se encuentra relativamente desconectada. Una población pequeña de agentes exploran en pocas áreas de investigación (clases tecnológicas). La actividad inventiva pequeña se encuentra distribuida de forma más o menos homogénea entre los agentes. Los agentes, sobre todo empresas, ENP e inventores, inician la exploración en áreas relativamente distantes ( $c f$. la columna del diámetro ${ }^{54}$ para este periodo de la tabla 1). Pocas de las grandes empresas patentan en este periodo. Dadas estas condiciones, la probabilidad de las patentes traslapadas es baja.

En el periodo 1992-2003, la actividad inventiva se incrementa de forma exponencial. Aumenta el número de nuevos agentes en el sistema (de 12 nuevos agentes en 1992 a 270 en 2003, con 258 nuevos agentes durante este periodo), al mismo tiempo que se tiende a la concentración progresiva del conocimiento en pocos agentes. Se cuadruplican las áreas de investigación (de 336 clases en 1992 a 1,230 en 2003). La red de conocimientos se conecta más (el diámetro de la red pasó de 4 a 3 de 1992 a 2003). Se comienza a estructurar áreas de investigación relevantes (sobre todo los vehículos completamente eléctricos y los vehículos híbridos).

\footnotetext{
52 Que se examinó más arriba.

53 Las citas forward muestran un comportamiento similar a las citas backward, pero desfasado en el tiempo (se considera un periodo). La razón de este hecho es que la probabilidad de una patente nueva de ser citada es menor que la de una patente más antigua.

${ }^{54}$ El diámetro de la red, la distancia más corta para llegar de un punto a otro cualquiera. En nuestro caso, es un indicador de la cercanía entre los conocimientos.
} 
Si solo se consideran estas características estructurales del VE se puede señalar que la probabilidad de enfrentar patentes traslapadas se incrementa. Pero este no es el único factor. Se deben considerar otras características, como los atributos de los agentes. Por ejemplo, las motivaciones de las ENP. Las ENP contribuyen al sistema con pocas patentes, pero que influyen sensiblemente en la trayectoria de la actividad inventiva: poseen el mayor número de citas forward. Así mismo, se puede considerar que en la medida en que las ENP públicas o privadas no comercializan su tecnología, no están motivadas a bloquear la explotación de una tecnología sino más bien a conceder licencias $^{55}$.

En el periodo 2004-2012, continúa el crecimiento exponencial de la actividad inventiva. De igual manera y a pesar de la fuerte concentración del conocimiento, ingresan nuevos agentes en el sistema (333 a lo largo del periodo) y se incrementan las áreas de investigación (clases tecnológicas), pero a una tasa menor (casi se duplicaron, de 1,294 en 2004 a 2,394 en 2012). A diferencia del periodo previo, el conocimiento se despliega de manera jerárquica ${ }^{56}$, lo que aumenta la probabilidad de patentes traslapadas, sobre todo en las áreas más densas y anidadas, como el procesamiento de datos. La dirección de la actividad inventiva migra de las patentes de contenido tangible a patentes intensivas en conocimiento intangibles (software). La naturaleza de los VE se transforma por ello.

En este periodo ingresan nuevos participantes - especialmente empresas del sector electrónico- en la actividad inventiva relacionada con el procesamiento de datos. Empresas que, como en el caso de Google ${ }^{57}$, pueden convertirse en productoras de VE, y que podrían empujar a las empresas tradicionales del sector automotriz a posiciones defensivas desde el punto de vista de la propiedad intelectual. Y, finalmente, la concentración de la propiedad intelectual en un grupo cada vez más reducido de agentes puede desembocar en diferentes prácticas: 1) licencias cruzadas $^{58}$ o 2) litigios.

En este periodo, crece la importancia de las alianzas respecto al conocimiento que proporcionan al sistema. Las alianzas, al compartir la propiedad de la actividad inventiva, permiten a sus participantes reducir el problema de las patentes traslapadas. Los agentes que integran una alianza tendrán menores incentivos a bloquearse mutuamente. Al mismo tiempo, es posible que la expansión de las alianzas incremente el riesgo de las patentes traslapadas de alianzas diferentes.

Es fundamental incluir la diversidad de los agentes en los estudios de las patentes traslapadas, puesto que, como en este caso, brinda información y enriquece la comprensión del fenómeno. Este estudio tuvo como objetivo, por una parte, sentar las bases para un análisis teórico más preciso que permita examinar cómo interaccionan la naturaleza del bien (VE), los atributos de los agentes y las reglas. Por otra parte, se buscó también refinar y proponer nuevas técnicas de análisis de las patentes traslapadas.

Finalmente, es necesario profundizar en el estudio de los sistemas de patentes que, si bien crean certidumbre respecto a los derechos de propiedad intelectual, también crean condiciones para bloquear la innovación. Una perspectiva que incorpore la teoría institucional y la teoría de los

\footnotetext{
55 Esto se cumple incluso con los patent trolls, un tipo de ENP que no genera conocimiento, sino que adquiere patentes de otros agentes como cualquier otro activo financiero para su posterior licenciamiento.

56 Como resultado se configuran y consolidan 3 áreas centrales de invención: los vehículos híbridos, los vehículos completamente eléctricos y el procesamiento de datos.

57 Aunque en la base de patentes aquí utilizada que va de 1976 a 2012 no se encuentran patentes de Google, en 2014 le fueron otorgadas 2 patentes (8825391 y 8688306) que contienen la clase 701/22 destinadas al diseño de vehículos autónomos.

${ }^{58}$ En particular, cuando ambos agentes tienen una cartera de patentes relativamente grande y complementaria.
} 
sistemas complejos puede tener buenos resultados tanto para representar y explicar el fenómeno como para diagnosticar y elaborar propuestas.

\section{Anexo 1.}

Los pasos generales que se siguieron para la construcción de la red de clases fueron:

a) Del sistema de información de patentes de la USPTO se descargaron las patentes del 1 de enero de 1976 al 20 de noviembre de 2012 correspondientes a las clases tecnológicas 180/65.1, $180 / 65.21$ y $701 / 22$ por medio del comando de búsqueda $(\mathrm{ccl} / 180 / 65.1$ or $\mathrm{ccl} / 180 / 65.21$ or ccl/701/22). La descarga se hizo de http://patft.uspto.gov/netahtml/PTO/search-adv.htm

b) Se extrajeron todas las clases tecnológicas y se ordenaron en una nueva base manteniendo los números de las patentes correspondientes.

c) Con los datos de dicha base, se construyó la matriz de adyacencia de las clases vinculadas por patentes. Es decir, a cada par de clases se le asignaba un vínculo si una patente contenía dicho par de clases.

d) Se introdujo esta matriz en el programa de análisis de redes NodeXL, anexando una columna en la que se especificaba el año que por primera vez se patentó en cada clase.

e) Se generó la red y sus estadísticos en el mismo programa para su análisis posterior.

\section{Referencias}

Arthur, B. (2011). The nature of technology: What it is and how it evolves. Nueva York: Free Press.

Bauer, P. (2007). How electronics is changing the automotive industry: From component suppliers to system partners, en Bernd Gottschalk, Ralf Kalmbach (eds.), Mastering automotive challenges (pp. 270-289). London: Kogan Page.

Bessen, J. y Maurer, M. J. (2008). Paten failure: How judges, bureaucrats and lawyers put innovators at risk. Nueva Jersey: Princenton University Press.

Blind, K., Edler, J., Frietsch, R. y Schmoch, U. (2006). Motives to patent: Empirical evidence from Germany. Research Policy, 35(2006), 655-672.

Chávez, A. y Lara, A. (2014). Propiedad intelectual y evolución de la naturaleza compleja de los vehículos eléctricos. Economía: Teoría y Práctica, 40, 103-136.

Frenken, K., Marengo, L. y Valente, M. (1999). Interdependencies, nearly-decomposobality and adaptacion. En Thomas Brenner (Ed.), Computational techniques for modelling learning in Economics (pp. 145-165). NY: Springer.

Frenken, K. (2006). Innovation, evolution and complexity theory. UK: Edward Elgar Publishing.

Giannitsis, T. y Kager, M. (2009) Technology and specialisation: dilemmas, options and risks? Expert Group 'Knowledge for Growth' [consultado 23 Dic 2013]. Disponible en: http://www.eurosfaire.prd.fr/7pc/doc/1262700001 _ kfg_report_no8.pdf

Hall Bronwyn, H., Helmers, C., von Graevenitz, G. y Bondibene, C. (2013). A study of patent thickets. The Intellectual Property Office.

Heller, M. A. y Eisenberg, R. (1998). Can patents deter innovation? The Anticommons in biomedical research. Science, 280(5364), 698-701.

Heller, M. A. (2008). The gridlock economy. Nueva York: Basic Books.

Heller, M. A. (1998). The tragedy of the anticommons: Property in the transition from marx to markets. Harvard Law Review, 111(3), 621-688.

Hess, C. y Ostrom, E. (2003). Ideas, artifacts, and facilities: Information as a common-pool resource. Law and Contemporary Problems, 16(111), 11-145.

Holland, J. H. (2004). El orden oculto, de como la adaptación crea la complejidad. México: FCE.

IPO. (2011). Patent thickets. Team intellectual property office patent informatics. Newport: IPO.

Juliussen, E. y Robinson, R. (2010). Is Europe in the driver's seat? The competitiveness of the European automotive embedded systems industry. Londres: Institute for Prospective Technological Studies, European Comission.

Kauffman, S. A. (1993). The origins of order: Self-organization and selection in evolution. Reino Unido: Oxford University Press. 
Lara, A. (2014). From complex mechanical system to complex electronic system: The case of automobiles. International Journal of Automotive Technology and Management, 14(1), 65-81.

Lara, A. y Salazar, C. E. (2013). Complejidad, instituciones y trayectoria tecnológica del automóvil: El caso de la batería de plomo-ácido, en F. Novelo, El Retorno del Desarrollo. pp. 101-121. México: UAM-X.

Low, B., Ostrom, E., Simon, C. y Wilson, J. (2003). Redundancy and diversity: Do they influence optimal management? En F. Berkes, J. Colding, y C. Folke (Eds.), Navigating Social-Ecological Systems: Building resilience for complexity and change (pp. 83-114). Nueva York: Cambridge University Press.

Osorio, H. y Lara, A. (2013). La tragedia de los anticomunes en la construcción del conocimiento del genoma humano. Argumentos, 73, 147-174, año 26.

Ostrom, E. (1990). Governing the commons: The evolution of institutions for collective acction. Reino Unido: Cambridge University Press.

Ostrom, E. (2005). Understanding institutional diversity. Nueva Jersey: Pricenton Unversity Press.

Ostrom, V. (1980). Artisanship and Artifact. Public Administration Review, 40, 309-317.

Page, S. E. (2011). Diversity and complexity. Nueva Jersey: Princenton University Press.

Pistoia, G. (2008). Battery operated devices and systems: From portable electronics to industrial products. Alemania: Elsevier.

Poteete, A. R., Janssen, M. A. y Ostrom, E. (2011). Working together: Collective action, the commons, and multiple methods in practice. Nueva Jersey: Princeton University Press.

Reyes, J. (2012). Diversidad y complejidad en el sector de baterías en el periodo 1976-2010. México: UAM [tesis doctoral].

Roland Berger Strategy Consultants. (2009). Powertrain 2020 - The future drives electric. Múnich: Ed. Roland Berger Strategy Consultants.

Shapiro, C. (2001). Navigating the patent thicket: Cross licenses, patent pools, and standard-setting. En A. B. Jaffe (Ed.), Innovation Policy and the Economy. (pp. 119-150). Cambridge: MIT Press.

Simon, Herbert, A. (1996). Las ciencias de lo artificial. Granada: Comares.

Ulrich, T. K. y Eppinger, S. D. (2009). Diseño y desarrollo de productos. México: Mc Graw Hill.

USPTO (s.f.), Environmentally Sound Technologies (ETS) Concordance», en United States Patent and Trademark Office. [Consultado 27 Nov 2012]. Disponible en: http://www.uspto.gov/web/patents/classification/international/ est_concordance.htm

Van Overwalle, G. (2009). Gene patents and collaborative licensing models: patent pools, clearinghouses, open source models and liability regimes. Reino Unido: Cambridge University Press.

Von Graevenitz, G., Stefan, W. y Harhoff, D. (2011). How to mesure patent thickets: A novel approach. Economics Letters, $111(1), 6-9$. 